Discussion Papers of the

Max Planck Institute for

Research on Collective Goods

2020/14

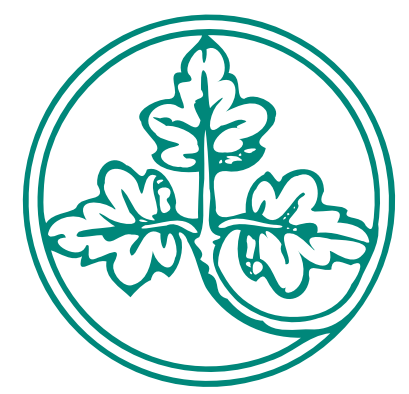

How Do Parents Perceive the Returns to Parenting Styles and Neighborhoods?

Lukas Kiessling 


\title{
How Do Parents Perceive the Returns to Parenting Styles and Neighborhoods?
}

\author{
Lukas Kiessling
}

June 2020 


\title{
How Do Parents Perceive the Returns to Parenting Styles and Neighborhoods?
}

\author{
Lukas Kiessling*
}

June 23, 2020

\begin{abstract}
This paper studies parental beliefs about the returns to two factors affecting the development and long-term outcomes of children: (i) parenting styles defined by the extent of warmth and control parents employ in raising children, and (ii) neighborhood quality. Based on a representative sample of 2,119 parents in the United States, I show that parents perceive large returns to the warmth dimension of parenting as well as neighborhood quality, and document that parenting is perceived to compensate for the lack of a good environment. Mothers expect larger returns than fathers, but there is no socioeconomic gradient in perceived returns despite a high degree of heterogeneity. Furthermore, I introduce a measurement error correction by leveraging beliefs measured in two different domains, and show that parents' perceived returns relate to their actual parenting styles. My results suggest that parental beliefs are an important determinant of parental decision-making, but cannot explain socioeconomic differences in parenting.
\end{abstract}

Keywords: Beliefs, Parenting styles, Neighborhoods, Child outcomes, Human capital

JEL-Codes: I24, I26, J13, J24, D19, R23

\footnotetext{
"Lukas Kiessling: Max Planck Institute for Research on Collective Goods, lkiessling@coll.mpg.de. I thank Viola Ackfeld, Anne Ardila Brenøe, Thomas Dohmen, Lorenz Goette, Joel Kaiyuan Han, Matthias Heinz, Katja Kaufmann, Jonathan Norris, Yasemin Özdemir, Pia Pinger, Sebastian Schneider, Matthias Sutter, as well as conference audiences at the 5th LEER Conference on Education Economics, the 3rd CRC TR 224 Conference, the 3rd Meeting of the Society of the Economics of the Household (SEHO), the 33th Annual Conference of the European Society of Population Economics (ESPE), and the 31st Conference of the European Association of Labour Economists (EALE) for helpful discussions and suggestions. Funding by the Deutsche Forschungsgemeinschaft (DFG, German Research Foundation) through CRC TR 224 (project A02) is gratefully acknowledged.
} 


\section{Introduction}

Parents play a crucial role for the development and success of children, as inequalities can be traced back to early life (Francesconi and Heckman, 2016; Kalil, 2015). Yet, not much is known about the factors determining how parents decide to raise their children. In particular, evidence on the parental decision-making process and the consequences of different parenting styles remains scarce, in part due to their complexity (Attanasio, 2015). In a recent study, Doepke and Zilibotti (2017) argue that the economic environment creates incentives to engage in different forms of parenting. As parents decide where to live and how to raise their children, it is important to understand how parents perceive their environments and parenting to interact 1

In this paper, I study how parents perceive the returns to two factors affecting the development and long-term outcomes of children: First, I focus on parenting styles describing strategies that parents use in raising their children (Baumrind, 1967), and second, I focus on the quality of the neighborhood in which a family lives. In addition, I examine their perceived substitutability or complementarity, analyze the heterogeneity in perceived returns, and investigate their relevance for parents' actual parenting style choices.

In order to investigate parental beliefs, I adopt a hypothetical scenario approach similar to Cunha, Elo, and Culhane (2013), Boneva and Rauh (2018), Bhalotra et al. (2020), and Attanasio, Boneva, and Rauh (2019). More specifically, I construct eight scenarios in which parents raise their children. Across scenarios, I vary the parenting style that parents adopt - commonly defined as different intensities of warmth and control employed in raising children (Maccoby and Martin, 1983) ${ }^{2}-$ as well as the quality of the neighborhood families are living in. In addition, I randomize the children's age and gender across respondents. For each of these scenarios, I then elicit parental expectations about the future earnings and expected life satisfaction of the child at the age of 30 as proxies for child achievement and well-being in adulthood 3

\footnotetext{
${ }^{1}$ In general, any observed choice may be consistent with different combinations of preferences and beliefs. Manski (2004) therefore argues that one cannot solely rely on observed behavior to infer underlying beliefs, and advocates for a direct elicitation of beliefs.

2Parenting styles have a long tradition in developmental psychology going back to Baumrind (1967). Initially, she identified three parenting styles, while Maccoby and Martin (1983) extend her original typology to four styles defined according to two dimensions - the extent of warmth, on the one hand, and control used in raising children, on the other. Depending on their intensities, these two dimensions define four distinct parenting styles: authoritative (high warmth, high control), permissive (high warmth, low control), authoritarian (low warmth, high control), and neglecting (low warmth, low control). The psychology literature often refers to these dimensions as responsiveness and demandingness instead of warmth and control.

${ }^{3}$ This approach of eliciting future wage expectations dates back to Dominitz and Manski (1996) and has subsequently been used in a range of studies focusing on returns to human capital investments
} 
This design has several noteworthy features: First, by eliciting parents' beliefs for all eight scenarios and varying one dimensions at a time, I can infer parents' perceived returns to one particular dimension while controlling for (unobserved) heterogeneity across respondents. Second, comparing scenarios that change several factors at the same time allows me to investigate the perceived substitutability or complementarity of parenting styles and neighborhoods. Third, having access to several elicited beliefs per parent, I can estimate how each parent perceives these returns and subsequently link them to their characteristics and actual parenting styles. I implement the scenarios in a survey of 2,119 parents with school-aged children in the United States, who are selected to be representative in terms of their gender, age, income, and region.

I find that parents expect considerable returns to the warmth dimension of parenting, but not to control. An increase of one standard deviation in warmth is associated with parents expecting 15.3 percent higher earnings for children at the age of 30 , whereas increasing control is not perceived as yielding any returns. In addition, my estimates show that parents expect earnings to increase by 22.6 percent when raising a child in a relatively good neighborhood. When analyzing the interaction of the different factors, parents seem to adapt their expectations. Parents perceive warmth and control as complements, increasing expected earnings by an additional 4.6 percentage points if combining high levels of both warmth and control. Moreover, parenting is perceived as being more effective in low-quality neighborhoods. The perceived return to warmth (control) is 1.4 (1.5) percentage points higher in low-quality neighborhoods, corresponding to an increase of about a tenth of the perceived return to warmth. Parents therefore expect their parenting to compensate at least in part for deprived environments. Yet, authoritative parenting styles featuring warmth and control are perceived as being more effective in high quality neighborhoods. In addition, I show that these results are not restricted to the monetary domain, but carry over to the life satisfaction domain.

How do these perceived returns vary by age and gender of the child? First, my results reveal a pronounced age gradient: high levels of warmth are perceived as more effective for younger children, while exerting control is especially important for older, teenage children living in adverse environments. I do not find differences in perceived returns by child gender. Moving to heterogeneity by parental characteristics, I find pronounced differences in perceived returns by the parent's gender. Mothers expect higher returns to warmth and neighborhoods than fathers, while there are no differences in the control dimension of parenting styles. Although there (e.g., Attanasio and Kaufmann, 2014; Hastings et al., 2016; Jensen, 2010; Kaufmann, 2014; Nguyen, 2008). 
is a large dispersion in perceived returns, I do not find systematic associations with other sociodemographic characteristics, which is in line with findings by Attanasio, Boneva, and Rauh (2019), but contrasts with Boneva and Rauh (2018). My findings imply that parental beliefs about returns to parenting styles and neighborhoods are similar for parents from different socioeconomic backgrounds and thus unlikely to explain socioeconomic differences in parenting behavior.

Despite this absence of socioeconomic differences in perceived returns, there are systematic variations. In particular, I show that parenting values - parents' altruism and paternalism towards their own child - are strongly related to perceived returns: Altruistic parents expect high payoffs for being responsive (high warmth) and living in good neighborhoods, while paternalistic parents expect larger returns to exerting control. These patterns therefore provide empirical support for assumptions made in Doepke and Zilibotti (2017), who conceptualize parental altruism and paternalism as key parameters for parents' choice of parenting styles.

Finally, I investigate whether perceived returns are relevant for parents' actual parenting style. Importantly, I find that perceived returns to both parenting dimensions are related to actual parenting behavior in the respective dimension: parents who expect larger returns to warmth (control) are more likely to raise their own children with warmth (control), highlighting that parental beliefs are consistent with actual behavior.

These results contribute to three strands of the literature. First, the paper relates to a growing literature on subjective expectations in the context of human capital formation. 4 It is most closely connected to studies of parental beliefs about the process of human capital formation pioneered by Cunha, Elo, and Culhane (2013). Boneva and Rauh (2018) and Attanasio, Boneva, and Rauh (2019) build on their hypothetical scenario approach to study the timing (childhood or adolescence) or type of investment (time or money), while Bhalotra et al. (2020) consider different forms of time investments (intensity of breastfeeding and child interaction). By contrast, I hold time investments constant and study a different margin by allowing the mode of interaction, i.e., the parenting style, to vary. The rationale behind this is that a time investment of one hour can have different effects, depending on the intensity of parent-child interactions and thus I pay attention to the quality rather than the quantity margin of parental investments.

${ }^{4}$ The literature discussed here builds on a growing literature analyzing students' subjective expectations about schooling decisions (Attanasio and Kaufmann, 2014; Giustinelli, 2016; Jensen, 2010; Kaufmann, 2014) and major choices (Arcidiacono, Hotz, and Kang, 2012; Beffy, Fougère, and Maurel, 2012; Hastings et al., 2016; Stinebrickner and Stinebrickner, 2014; Wiswall and Zafar, 2015; Zafar, 2013), or family and job preferences as well as the resulting gender differences (Kiessling et al., 2019, Wiswall and Zafar, 2018a b). 
Apart from analyzing a new and distinct margin of parental beliefs, I also add methodologically to the literature on subjective expectations. Specifically, I demonstrate how eliciting a second belief measure in a different domain allows to recover perceived returns that are domain-independent and corrected for measurement error: While the main belief measure is elicited in the earnings domain as is common in the literature, I elicit a second set of beliefs that measures the returns to the same underlying factor, but in a different domain (life satisfaction). Using perceived returns from these two domains and applying a error-in-variables IV strategy to correct for measurement error similar to Gillen, Snowberg, and Yariv (2019), I can reduce the attenuation bias that is common in the analysis of subjective expectations.

Second, I contribute to a series of papers explicitly incorporating parenting styles in addition to parental investments in their analyses of child outcomes. These studies analyze the development (Cobb-Clark, Salamanca, and Zhu, 2019; Cunha, 2015; Del Bono et al., 2016; Ermisch, 2008; Fiorini and Keane, 2014) and intergenerational transmission of skills and preferences (Brenøe and Epper, 2019; Falk et al., forthcoming; Zumbuehl, Dohmen, and Pfann, 2018), a child's behavior (Dooley and Stewart, 2007) or school outcomes (Cosconati, 2012). While these papers, as well as the developmental psychology literature, are primarily concerned with the consequences of particular investments or parenting styles for child outcomes, Doepke and Zilibotti (2017) and Doepke, Sorrenti, and Zilibotti (2019) choose a different approach. They focus on parental decision-making and argue that economic incentives created by the environment shape parents' parenting style choices.5 The present paper complements these papers by presenting evidence on the perceived long-term consequences of different parenting styles in two relevant domains - earnings and life satisfaction - and show that these perceived returns are informative for parents' actual parenting style choices. Moreover, my results provide support for modeling choices made in Doepke and Zilibotti (2017), namely that parental altruism and paternalism are key to understanding the choice of parenting styles.

\footnotetext{
${ }^{5}$ In particular, their model focuses on inequality and occupational mobility (in terms of an incumbency premium) as two features of the environment that create such incentives. Using data from the World Value Survey, Doepke and Zilibotti (2017) provide cross-country evidence that these two measures correlate with average parenting styles in a country. Agostinelli et al. (2020) build on this idea and study the interaction of parenting styles and peer effects, and thus highlight very specific and local neighborhoods of school peers. Cuellar, Jones, and Sterrett (2015) review the psychological literature on the relationship between parenting styles and neighborhoods. While a general finding in developmental psychology is that an authoritative form of parenting is most effective in raising successful children, there exists a large variety in adopted parenting styles (e.g., Chan and Koo, 2011; Dornbusch et al., 1987; Lamborn et al., 1991; Steinberg et al., 1991). The present study focuses on parental perceptions of these interactions.
} 
Lastly, the paper relates to the literature showing how neighborhoods affect longterm outcomes of children (see, e.g., Chetty et al.,2018; Chetty and Hendren, 2018a b; Deutscher, forthcoming, for evidence that neighborhood exposure affects a variety of social and economic outcomes) and the literature that analyzes parents' behavioral responses. Kling, Liebman, and Katz (2005), Pop-Eleches and Urquiola (2013), and Han (2019) provide evidence that parents are more involved in their children's upbringing in low-quality neighborhoods. By contrast, Patacchini and Zenou (2011) suggest that parental involvement actually increases with neighborhood quality. I contribute to this discussion by providing first evidence on parental perceptions of both neighborhood effects, as well as their interactions with parenting decisions. Moreover, my results show that parents perceive the returns to high warmth or high control parenting as being relatively larger in low quality neighborhoods. However, these effects are reversed when I analyze authoritative parenting styles, characterized by high levels of warmth and control. This indicates that conflicting findings in the literature could be due to a focus on different margins of parenting. Collectively, these studies as well as my paper therefore suggest that the way in which parents raise their children interacts with neighborhood quality, thus pointing towards an additional mediator of neighborhood effects besides schools (e.g., Laliberté, 2018) or peers (e.g., Agostinelli, 2018).

In the next section, I describe the main survey instrument as well as the data collection process. Section 3 describes the empirical strategy. In Section 4 , I document parents' beliefs about the returns to parenting styles and neighborhoods, before Section 5 turns to an individual-level analysis. Section 6 examines the relevance of individual perceived returns for parental decision-making. Finally, Section 7 concludes.

\section{Survey Description and Data}

My aim is to study parental beliefs about the effectiveness of different parenting styles and to analyze their interaction with the economic environment. In order to study these beliefs, I conduct a survey with a representative survey with a sample of over 2,000 parents in the United States. In this section, I describe the survey instrument and the sample for this study.

\subsection{Survey Instrument}

Analyzing parental beliefs is difficult for several reasons: First, inferring beliefs from observed behavior can be challenging, as different sets of preferences and beliefs 
can in principle rationalize a given action (Manski, 2004). Second, eliciting beliefs only about the consequences of one's own actual parenting style ignores important counterfactual beliefs that are an integral part of the decision-making process (Arcidiacono, Hotz, and Kang, 2012). Third, collecting beliefs about the parents' own behavior towards their children might trigger motivated or self-serving beliefs, resulting in over- or understating of their beliefs. In order to circumvent these issues, I adopt a hypothetical scenario approach used by, e.g., Cunha, Elo, and Culhane (2013), Boneva and Rauh (2018), Attanasio, Boneva, and Rauh (2019), as well as Bhalotra et al. (2020), and elicit beliefs about the consequences of different parenting styles directly. These scenarios have the advantage of allowing me to elicit returns over different dimensions and counterfactuals by varying one dimension at a time while holding other factors constant. In addition, by asking about the consequences of a hypothetical family, I reduce the scope for self-serving beliefs.

The survey instrument consists of different scenarios varying the parenting style of parents, as well as the quality of the environment in which a family is living. I adopt the typology of parenting styles introduced by Baumrind (1967) and further specified by Maccoby and Martin (1983) and vary whether parents raise their children with high or low warmth, as well as high or low control. The combination of these two dimensions results in four distinct parenting styles: neglecting (low warmth, low control), authoritarian (low warmth, high control), permissive (high warmth, low control), and authoritative (high warmth, high control). In order to study how the effectiveness of these different parenting styles depends on the quality of the neighborhood, I elicit parents' expectations about the consequences of the four parenting styles in two different environments: one neighborhood (the "good" neighborhood) describes an environment with low unemployment and little crime, while the other has relatively high unemployment and more crime ("bad" neighborhood). This allows me to test whether parents believe that the effectiveness of different parenting styles hinges on the environment in which a family is living, as suggested in Doepke and Zilibotti (2017). Moreover, this enables me to examine whether parents perceive one parenting style as optimal, independently of the socioeconomic environment. Table 1 summarizes the resulting eight scenarios.

More specifically, I present respondents two hypothetical average American families, each having a single child whose age and gender are randomly determined, as described below. The two families differ only in the neighborhood in which they are living. One family, the "Joneses", lives in a good neighborhood that has a relatively low unemployment rate (2\%), as well as a low crimes rate (10 violent crimes per 10,000 inhabitants). The other family, the "Smiths", lives in a relatively deprived 
Table 1: Survey scenarios

Bad neighborhood $\left(n^{L}\right)$

\begin{tabular}{c|c|c} 
& $\begin{array}{c}\text { Low } \\
\text { control } \\
\left(c^{L}\right)\end{array}$ & $\begin{array}{c}\text { High } \\
\text { control } \\
\left(c^{H}\right)\end{array}$ \\
\hline $\begin{array}{c}\text { Low warmth } \\
\left(w^{L}\right)\end{array}$ & $y_{1}$ & $y_{2}$ \\
\hline $\begin{array}{c}\text { High warmth } \\
\left(w^{H}\right)\end{array}$ & $y_{3}$ & $y_{4}$
\end{tabular}

Good neighborhood $\left(n^{H}\right)$

\begin{tabular}{c|c|c} 
& $\begin{array}{c}\text { Low } \\
\text { control } \\
\left(c^{L}\right)\end{array}$ & $\begin{array}{c}\text { High } \\
\text { control } \\
\left(c^{H}\right)\end{array}$ \\
\hline $\begin{array}{c}\text { Low warmth } \\
\left(w^{L}\right)\end{array}$ & $y_{5}$ & $y_{6}$ \\
\hline $\begin{array}{c}\text { High warmth } \\
\left(w^{H}\right)\end{array}$ & $y_{7}$ & $y_{8}$
\end{tabular}

Notes: This table summarizes scenarios $j(j=1, \ldots, 8)$ in which respondents are asked to provide expected earnings for children at age $30\left(y_{j}\right)$ for different parenting style combinations (low and high warmth/control) and neighborhoods (low or high neighborhood quality).

neighborhood with higher unemployment (10\%), as well as a higher crime rate (60 violent crimes per 10,000 inhabitants) 6 The scenarios stress that apart from living in different neighborhoods, both families have similar levels of education and income, and both families invest equal levels of time and money in their children.

In addition, I vary the warmth and control dimension of parenting styles across scenarios. In order to describe different parenting styles, I adopt descriptions based on established measures of parenting styles for warmth and control. Specifically, I conducted a pilot study in which I tested several descriptions of behaviors corresponding to the two parenting style dimensions, and chose the item that had the highest predictive power for each dimension. Furthermore, this pilot study elicited the frequency distributions of the respective behaviors, which were subsequently used to calibrate the differences between scenarios to one standard deviation. This procedure yields four parenting styles varying the level of warmth and control: neglecting (low warmth, low control), permissive (high, low), authoritarian (low, high), and authoritative parenting (high, high).

Taken together, the hypothetical scenarios vary (a) the parenting style a family adopts by varying the intensity of the two dimensions warmth and control from low to high, and (b) the quality of the family's neighborhood ("good" or "bad" characterized by high or low unemployment and crime). Appendix A presents the wording of the scenarios. An important feature is that respondents are asked not only about one of the

${ }^{6}$ The underlying idea is that unemployment and crime rates correspond to measures of a latent neighborhood quality factor that potentially subsumes several other facets such as school quality or the availability of amenities. Similar proxies for neighborhood quality have been used before (e.g., Han, 2019). 
scenarios, but answer all of them. This allows me to infer the perceived returns over all three dimensions warmth, control, and neighborhood quality for each individual. By comparing individual responses across these scenarios, I am able to infer perceived returns of the three dimensions as well as their relationship in terms of their perceived substitutability and complementarity. In Appendix B, I outline a brief theoretical framework that shows how the comparisons of these scenarios allow me to infer perceived returns to living in good neighborhoods and parenting styles, as well as their relation in terms of their substitutability and complementarity.

\subsection{Outcomes}

The survey instrument elicits respondents' expectations for two outcomes of the hypothetical children at age 30. First, as a main outcome, I elicit parents' expectations about the expected gross yearly earnings of the children in terms of today's USD if they are working full-time. This measure allows me to calculate monetary returns over the different domains. I also elicit the expected life satisfaction at age 30 as a second outcome (measured on a scale from 1, low, to 100, high) to test whether the inferred returns carry over to other domains. Moreover, I combine both measures to correct for measurement error as I describe in Section 3 .

\subsection{Randomization}

In order to analyze the extent to which parental beliefs depend on the characteristics of the child, I implement two randomizations: First, I randomly determine the gender of the child.7 One group answers the scenarios in which both families have sons ("John" or "Simon"), while for another group, the families have daughters ("Emily" or "Sarah").8 By comparing elicited beliefs between respondents seeing a son or a daughter, I can study gender differences in perceived returns. Second, the age of the child in the scenarios is randomly drawn from a uniform distribution between 6 and 16 years. The rationale for this is to analyze whether specific parenting styles are perceived more effective in certain periods as the literature on parental investments has identified periods during childhood which are crucial for skill development and long-term outcomes of children (Cunha and Heckman, 2007; Cunha, Heckman, and Schennach,

${ }^{7}$ The randomization of gender and age is on the level of the respondent and not on the level of the hypothetical family. In other words, both families a respondent sees have either sons or daughters only, and these children have the same age.

${ }^{8}$ These names correspond to the most popular names at the beginning of the 2000 s, i.e., at a time when the hypothetical children of the scenarios were born. 
2010). Similarly, this helps to analyze whether parents perceive neighborhoods to be particularly important at certain ages.

\subsection{Additional Survey Elements}

In addition to the hypothetical scenarios described above and standard socioeconomic characteristics, the survey elicits respondents' actual parenting styles. To do this, I adopt two established measures of parenting styles as used in the German Socioeconomic Panel Study (SOEP). In particular, I use the short versions of the warmth and control dimension of parenting styles employing three- and four-items scales based on Perris et al. (1980) and Schwarz et al. (1997), respectively. Moreover, I elicit several parenting values such as the parents' belief about the malleability of their child's skills, as well as the degree of altruism and paternalism towards their children.9

Furthermore, I ask parents to assess the quality of the neighborhood in which they are living by eliciting their agreement to the three statements (i) "My neighborhood is a good place to raise children", (ii) "I feel safe in my neighborhood", and (iii) "My child attends a school of good quality", which I use to extract a factor for subjective neighborhood quality. Additionally, based on respondents' postcodes, I can link several neighborhood characteristics provided by Chetty and Hendren (2018a,b).

\subsection{Summary Statistics}

In October and November 2018, I collected a sample of 2,119 parents in the United States in collaboration with the market research company Research Now. To be eligible to take part in the study, respondents have to share a household with at least one child aged between 6 to 16, and respondents were sampled to be representative in terms of their gender, age, household income, and geographic distribution. Table 2 presents sociodemographic statistics of the final sample and the Current Population Survey (CPS): $61 \%$ of the respondents are female, with an average age of 40 years. The average household has an annual income of USD 82,644 and matches the geographic distribution across census regions similar to the Current Population Survey (CPS). Moreover, the sample also matches several non-targeted characteristics, such as the share of married respondents (75\%) and the average number of children (2.13), but

\footnotetext{
${ }^{9}$ These values are measured using the agreement of parents to the following statements: "I am usually willing to sacrifice my own desires to satisfy those of my child" (altruism), "As a parent, I sometimes need to be strict if my child acts against what I think is good for it" (paternalism), and "My child develops at its own pace, and there is not much I can do about that" (malleability of skills).
} 
has slightly higher level of education and a lower level of employment than the CPS sample.

Table 2: Summary statistics

\begin{tabular}{lcccc}
\hline & \multicolumn{2}{c}{ Sample } & & CPS \\
\cline { 2 - 3 } & Mean & SD & & Mean \\
\hline Sociodemographic variables & & & \\
Female & 0.61 & 0.49 & 0.57 \\
Age & 40.25 & 7.38 & & 40.89 \\
Employed & 0.72 & 0.45 & & 0.79 \\
College degree & 0.52 & 0.50 & 0.36 \\
Household income (in USD) & 82644 & 55117 & 78018 \\
Family structure & & & \\
Married & 0.75 & 0.43 & 0.74 \\
Cohabitating & 0.08 & 0.27 & \\
Single parent & 0.16 & 0.37 & \\
Number of children & 2.13 & 1.08 & & 2.05 \\
Share of female children & 0.46 & 0.37 & \\
Geographic distribution across & census regions & \\
Northeast & 0.16 & 0.37 & & 0.15 \\
Midwest & 0.19 & 0.40 & 0.21 \\
South & 0.39 & 0.49 & 0.37 \\
West & 0.26 & 0.44 & 0.27 \\
\hline Observations & 2119 & & \\
\hline
\end{tabular}

Notes: This table presents summary statistics of the sample collected for this study and representative statistics of American parents based on the Current Population Survey (CPS).

\section{Empirical Strategy}

In order to analyze parental beliefs, I estimate the perceived returns to different parenting styles and neighborhoods by comparing an individual's beliefs in different scenarios to each other. I therefore identify perceived returns from the within-respondent variation in beliefs. More specifically, let $w_{j}$ and $c_{j}$ be equal to 1 if scenario $j$ corresponds to a parenting style with high warmth or high control, respectively, and zero otherwise. Analogously, let $n_{j}$ be equal to 1 if scenario $j$ corresponds to a high-quality neighborhood, and zero otherwise. Moreover, $y_{i j}$ denotes respondent $i$ 's expectation over the gross yearly earnings of a child at age 30 in scenario $j$. My main specification 
is then given by

$$
\begin{aligned}
\log \left(y_{i j}\right)= & \beta_{w} w_{j}+\beta_{c} c_{j}+\beta_{n} n_{j} \\
& +\beta_{w c}\left(w_{j} \times c_{j}\right)+\beta_{w n}\left(w_{j} \times n_{j}\right)+\beta_{c n}\left(c_{j} \times n_{j}\right)+f_{i}\left(X_{i}\right)+\epsilon_{i j} .
\end{aligned}
$$

The coefficients of interest are $\beta_{w}, \ldots, \beta_{c n}$, which describe the parents perceptions about the returns to the different factors. While $\beta_{k}$ with $k=w, c, n$ denote the first-order returns to warmth, control, and neighborhoods, the coefficients on the interaction terms $(k=w c, w n, c n)$ capture whether two dimensions are complements $\left(\beta_{k}>0\right)$ or substitutes $\left(\beta_{k}<0\right)$. Positive coefficients on interaction effects therefore imply that parents expect the return of two dimensions to increase when they are paired; negative coefficients mean that the returns are jointly lower than separately. The term $f_{i}\left(X_{i}\right)$ either controls for a vector of individual-specific characteristics $\left(f_{i}\left(X_{i}\right)=X_{i}^{\prime} \gamma\right)$ or individual fixed effects $\left(f_{i}\left(X_{i}\right)=\gamma_{i}\right)$ to absorb any observed or unobserved heterogeneity across individuals, respectively. Finally, $\epsilon_{i j}$ is an idiosyncratic error term clustered on the individual level.

Estimating equation (1) on the whole sample yields perceived returns to parenting and neighborhoods for a representative set of parents in the United States. In the second part of the analysis, I will also lever the individual panel dimension of the data to infer individual-level perceived returns that I can subsequently link to their determinants and actual decision-making. For this, I estimate a simplified version of equation (1) for each respondent separately, and winsorize the resulting returns at the 1 and 99\% level to account for outliers. This recovers individual-level perceived returns denoted by $R_{\text {warmth, } i}, R_{\text {control, } i}$, and $R_{\text {neighb., } i}$ for warmth, control, and neighborhoods. 10 In order to study whether and to what extent perceived returns are related to parental characteristics, I estimate

$$
R_{k, i}=\alpha_{0}+\alpha_{1} X_{i}+\eta_{k, i}
$$

in which $R_{k, i}$ denotes the perceived return of individual $i$ to dimension $k \in$ \{warmth, control, neighborhood $\}$, estimated based on equation (1), and $X_{i}$ is a vector of parental characteristics. I consider two sets of variables: First, I employ sociodemographic

\footnotetext{
${ }^{10}$ This approach differs from Attanasio, Boneva, and Rauh (2019) and Boneva and Rauh (2018). They calculate returns to each dimension by calculating log differences between high and low characteristics and averaging over the other two dimensions. By contrast, I estimate the same specification as used for the whole sample to obtain individual-level returns and thereby control for the presence of perceived interaction effects. While the individual-level returns are estimated both for the first-order returns ( $R_{k, i}$ for $k=$ warmth, control, neighborhood) as well as interactions $(k=w c, w n, c n)$, I restrict my analysis to first-order returns as they dominate over interactions effects in size, as I will show in Table 3 . and I lack statistical power to conduct an analysis for interactions on the individual level.
} 
characteristics such as gender, age, and education; second, I associate returns with respondents' parenting values (malleability of skills, altruism, and paternalism towards a child). In equation (2), $\alpha_{1}$ informs about the importance of parental characteristics $X_{i}$ to explain parents' perceived returns.

In a last step, I aim at examining the relevance of these perceived returns for parents' actual parenting styles. However, there are two issues that complicate this analysis. First, parents likely take other dimensions apart from expected earnings (as a proxy of child achievement) into account when deciding about their parenting style. Second, individual-level perceived returns are estimated on a small number of observations only and therefore are likely to contain sizable measurement error. In the following, I outline an instrumental variable strategy to reduce this measurement error and recover a more general notion of perceived returns that is not restricted to a single domain.

As explained in the previous section, I elicit beliefs in two distinct domains: one set captures parental beliefs in the earnings domain, while the other one elicits the corresponding beliefs in the life satisfaction domain. These two domains are likely to be correlated, but capture distinct facets of returns to parenting (child achievement and child well-being). The core idea of my instrumental variable strategy is to isolate the common variation in perceived returns from both domains. This variation corresponds to a more general notion of perceived returns to a particular dimension of parenting styles and thus is more appropriate when analyzing the link of perceived returns and actual parenting styles.

This IV strategy closely follows Gillen, Snowberg, and Yariv (2019), who termed this the "obviously related instrumental variables" approach. In a first step, I duplicate observations yielding $2 N$ observations. I then use the perceived returns in each domain ( $R_{k, i}^{d}$ with $d \in\{E, L S\}$ for the earnings and life satisfaction domain, respectively) once as a regressor and once as an instrument. The outcome in these regressions is one of two standardized measures of actual parenting styles ( $P S_{\text {warmth, } i}$ for the warmth dimension and $P S_{\text {control }, i}$ for the control dimension of parenting styles), which correspond to the first principal components when performing a factor analysis on the four (three) items of the warmth (control) parenting style scale elicited in the survey 11 For each dimension of parenting styles, $P S_{k, i}$ with $k=$ warmth, control, I

\footnotetext{
${ }^{11}$ Appendix Figure E.1 and Appendix Table E.1 show that an exploratory factor analysis on all seven items indeed recovers two factors corresponding to warmth and control from the set of survey items used to elicit a respondent's parenting style.
} 
estimate

$$
\begin{aligned}
& \left(\begin{array}{c}
P S_{k, i} \\
P S_{k, i}
\end{array}\right)=\left(\begin{array}{c}
\delta_{0}^{E} \\
\delta_{0}^{L S}
\end{array}\right)+\delta_{1}\left(\begin{array}{c}
R_{k, i}^{E} \\
R_{k, i}^{L S}
\end{array}\right)+\left(\begin{array}{c}
\delta_{2}^{E} X_{i} \\
\delta_{2}^{L S} X_{i}
\end{array}\right)+v_{k, i} \\
& \text { instrumenting }\left(\begin{array}{c}
R_{k, i}^{E} \\
R_{k, i}^{L S}
\end{array}\right) \text { with } Z=\left(\begin{array}{cc}
R_{k, i}^{L S} & 0_{N} \\
0_{N} & R_{k, i}^{E}
\end{array}\right) .
\end{aligned}
$$

Some remarks are in order. First, this specification remains agnostic about the importance of both domains, but instead estimates the joint coefficient of perceived returns in the earnings and life satisfaction domain. In fact, the coefficient $\delta_{1}$ represents the average of separate IV estimates and yield a consistent estimate of $\delta_{1}$ (see Gillen, Snowberg, and Yariv, 2019). Second, to take into account that each observation is duplicated, I bootstrap standard errors. Third, Gillen, Snowberg, and Yariv (2019) propose this strategy to elicit several measurement of the same construct (e.g., risk preferences in several experiments). In contrast, I elicit a measurement in a different domain and use this IV strategy to obtain the measurement error-corrected latent return independently of any particular domain 12

\section{Parental Beliefs about the Effectiveness of Parenting Styles and Neighborhoods}

In this section, I study parental beliefs about the effectiveness of different parenting styles and neighborhoods. I begin by documenting the beliefs in the scenarios elicited in the survey and estimate returns to different levels of warmth, control, and neighborhood quality. In a second step, I examine whether the perceived returns for boys and girls, as well as younger and older children, differ from each other based on randomizations across respondents.

\subsection{Representative Evidence on Perceived Returns}

How do parents' expectations vary over the scenarios, and what returns do they associate with different parenting styles and neighborhoods? Figure 1 depicts the mean parental beliefs for each of the eight scenarios from Table 1. Several findings emerge: First, average parental beliefs for earnings of a child at age 30 vary strongly

\footnotetext{
${ }^{12}$ One drawback of my approach is that I elicit parental beliefs in both domains in the same survey. Thus, the IV strategy employed here does not help to reduce survey-based measurement error. Ideally, one would elicit both belief domains twice in two separate surveys, which was not possible for logistical reasons.
} 
across scenarios ranging between USD 40,000 and USD 57,000, with an average of USD 47,810 13 Second, comparing the same parenting styles across neighborhoods reveals that parents expect large returns to neighborhoods. Being raised in a relatively good neighborhood increases expected earnings by USD 7,000 to USD 8,000 on average. Third, there are sizable returns to different parenting styles. In particular, parents expect authoritative parenting with high levels of warmth and control to compensate partly for raising children in low-quality neighborhoods. Moreover, the patterns suggest that the different dimensions interact with each other.

Figure 1: Parental beliefs about expected earnings

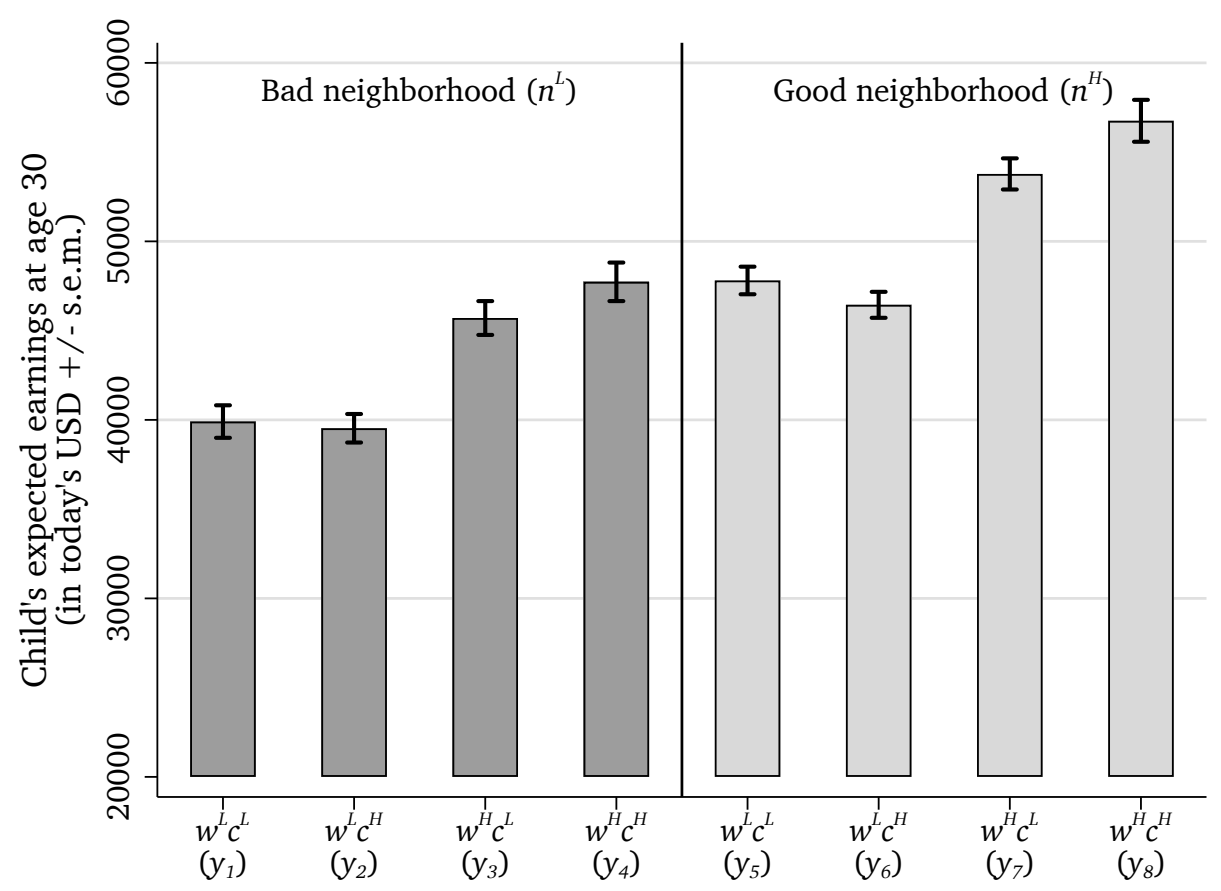

Notes: This figure presents parents' expectations about a child's earnings at age 30 in each of the eight scenarios $\left(y_{j}, j=1, \ldots, 8\right)$. The first four bars correspond to scenarios with low neighborhood quality, while the latter four bars correspond to scenarios with high neighborhood quality. Moreover, $w^{k} c^{l}(k, l=\mathrm{L}, \mathrm{H})$ indicate different parenting styles with a low $\left(w^{\mathrm{L}}\right)$ or high level of warmth $\left(w^{\mathrm{H}}\right)$ and a low $\left(c^{\mathrm{L}}\right)$ or high level of control $\left(c^{\mathrm{H}}\right)$, respectively; cf. Table 1. Error bars indicate standard errors to the mean.

In order to analyze these patterns in more detail, Table 3 presents OLS estimates as specified in equation (1). In columns (1) through (3), I focus on perceived returns to primary dimensions only, while columns (4) to (6) acknowledge the presence of interactions between different dimensions of parenting styles as well as neighborhoods. Finally, column (7) investigates the interaction of all three dimensions and therefore

\footnotetext{
${ }^{13}$ Conditional on working, respondents in the CPS earn approximately USD 46,200 at age 30 indicating that parents' beliefs are well-calibrated on average. For more details on the accuracy of these beliefs and the inferred returns, see Section 4.5
} 
asks whether authoritative parenting (high warmth and high control) is perceived to be more effective in good neighborhoods.

I find that parents perceive large returns to the warmth and neighborhood dimensions, but no returns from exerting control. Increasing the warmth dimension of parenting by one standard deviation in column (1) increases a child's expected earnings by 16.9 percent, while the estimated perceived return to control is statistically indistinguishable from zero with a 95\% confidence interval ranging from -0.2 to 1.2 percent. The perceived return to neighborhoods amounts to 21.1 percent. Neither the inclusion of sociodemographic controls in column (2) nor taking out all individual-level unobserved heterogeneity by including individual fixed effects in column (3) affects the coefficients of interest, i.e., the returns to warmth, control, and neighborhoods.

Table 3: Parental beliefs about the returns to parenting styles and neighborhoods

\begin{tabular}{lccccccc}
\hline & \multicolumn{7}{c}{ log. of expected earnings at age 30 $\left(\log \left(y_{i j}\right)\right)$} \\
\cline { 2 - 8 } & $(1)$ & $(2)$ & $(3)$ & $(4)$ & $(5)$ & $(6)$ & $(7)$ \\
\hline High warmth & $0.169^{* * *}$ & $0.169^{* * *}$ & $0.169^{* * *}$ & $0.153^{* * *}$ & $0.153^{* * *}$ & $0.153^{* * *}$ & $0.163^{* * *}$ \\
& $(0.007)$ & $(0.007)$ & $(0.007)$ & $(0.008)$ & $(0.008)$ & $(0.008)$ & $(0.009)$ \\
High control & 0.005 & 0.005 & 0.005 & -0.011 & -0.011 & -0.011 & -0.000 \\
& $(0.004)$ & $(0.004)$ & $(0.004)$ & $(0.007)$ & $(0.007)$ & $(0.007)$ & $(0.008)$ \\
Good neighborhood & $0.211^{* * *}$ & $0.211^{* * *}$ & $0.211^{* * *}$ & $0.226^{* * *}$ & $0.226^{* * *}$ & $0.226^{* * *}$ & $0.236^{* * *}$ \\
& $(0.008)$ & $(0.008)$ & $(0.008)$ & $(0.009)$ & $(0.009)$ & $(0.009)$ & $(0.010)$ \\
High warmth & & & & $0.046^{* * *}$ & $0.046^{* * *}$ & $0.046^{* * *}$ & $0.026^{* *}$ \\
$\quad \times$ High control & & & & $(0.010)$ & $(0.010)$ & $(0.010)$ & $(0.012)$ \\
High warmth & & & & $-0.014^{*}$ & $-0.014^{*}$ & $-0.014^{*}$ & $-0.035^{* * *}$ \\
$\quad \times$ Good neighborhood & & & & $(0.008)$ & $(0.008)$ & $(0.008)$ & $(0.009)$ \\
High control & & & & $-0.015^{* *}$ & $-0.015^{* *}$ & $-0.015^{* *}$ & $-0.036^{* * *}$ \\
$\quad \times$ Good neighborhood & & & & $(0.006)$ & $(0.006)$ & $(0.006)$ & $(0.009)$ \\
High warmth $\times$ High control & & & & & & & $0.041^{* * *}$ \\
$\quad \times$ Good neighborhood & & & & & & & $(0.013)$ \\
\hline Mean exp. income (in USD) & 47810 & 47810 & 47810 & 47810 & 47810 & 47810 & 47810 \\
Controls for heterogeneity & No & Controls & FE & No & Controls & FE & FE \\
Observations & 16952 & 16952 & 16952 & 16952 & 16952 & 16952 & 16952 \\
Individuals & 2119 & 2119 & 2119 & 2119 & 2119 & 2119 & 2119 \\
$R^{2} \quad$ & .052 & .14 & .73 & .052 & .14 & .74 & .74 \\
\hline
\end{tabular}

Notes: This table presents least squares regressions of log earnings expectations based on equation (1). Columns (1) through (3) focus on first-order effects. Columns (4) to (6) additionally include two-way interactions, while column (7) also adds a three-way interaction of warmth, control and neighborhoods. Columns (1) and (4) do not include any controls, columns (2) and (4) include respondent's age and gender, as well as indicators for being white, having a college degree, being employed, and being a single parent, log-household income, number of children in the household, and the share of children being female as control variables. Columns (3), (6), and (7) include individual fixed effects. Standard errors clustered by respondent in parentheses. *, **, and *** denote significance at the 10,5 , and 1 percent level.

Columns (4) through (6) additionally allow for interaction effects between warmth, control, and neighborhoods. These specifications allow, for example, that the warmth 
and control dimensions of parenting styles are perceived as substitutes or complements, or that returns to parenting differ across neighborhoods. First, I find that the primary effects on the dimensions are similar to the previous estimates without interactions. Second, when considering interaction terms, the estimates reveal a perceived complementarity between warmth and control. Parents expect an additional return of 4.6 percentage points if children are raised with high levels of both warmth and control. Hence, parents expect authoritative forms of parenting (i.e., high warmth and high control) to be most effective for children's long-term success. This is similar to what has been found in the psychology literature (Baumrind, 1967; Dornbusch et al., 1987; Lamborn et al., 1991). Interestingly, there are negative interactions of good neighborhoods with warmth and control. Thus, parents perceive parenting to be more important in relatively adverse environments and less necessary if the surrounding conditions are favorable. In other words, respondents expect parenting to partly compensate for the lack of a beneficial neighborhood. This is consistent with the observation that parents become more involved in raising their children when the quality of a neighborhood decreases (e.g., Han, 2019; Kling, Liebman, and Katz, 2005; Pop-Eleches and Urquiola, 2013). 14

Finally, column (7) introduces a triple interaction of high levels of warmth and control, as well as living in a good neighborhood, and thus measures the additional perceived return to authoritative parenting (high warmth and high control) in good neighborhoods. While the main conclusions remain qualitatively as well as quantitatively similar to the previous results, the additional interaction shows that parents perceive the complementarity of warmth and control to be stronger in favorable neighborhoods compared to detrimental ones. Thus, parents perceive neighborhoods and intensive parenting (i.e., authoritative parenting styles) as complements. As far as these perceptions correspond to actual returns, this result suggests that increasing segregation may help to explain why the rich adopt relatively more intensive parenting styles with higher investments, while the poor invest investments less as returns to parenting may be lower (see also the discussion in Doepke, Sorrenti, and Zilibotti, 2019). Moreover, this helps to reconcile the finding of cultural complementarity in Patacchini and Zenou (2011) with other studies documenting substitution effects between neighborhoods and parenting (e.g., Pop-Eleches and Urquiola, 2013) and my previous findings. While parents may try to compensate for the lack of a good environment by increasing their involvement in raising children, living in a high-quality neighborhood may induce an additional complementarity for very intensive forms of

\footnotetext{
${ }^{14}$ For example, Kling, Liebman, and Katz (2005) provide evidence that families in high-poverty neighborhoods spend a large fraction of their time monitoring their children and keeping them safe, i.e., they exert high levels of control in raising them.
} 
parenting (e.g., authoritative parenting). Thus, previous studies may have reached different conclusion of about the relationship between parenting and neighborhood quality by looking at different parenting behaviors.

\subsection{Perceived Returns by the Child's Gender and Age}

While the previous estimates are average returns across all scenarios, the design of the survey allows me to go one step further. In particular, I vary both the gender (male/female) as well as the age of the child in the scenario (6-16 years) across respondents. Table 4 analyzes whether parental expectations differ across these randomizations. As shown in columns (1) to (3), parents expect boys to earn more than girls when they are grown up. They expect boys to earn on average 49,492 USD and girls to earn around 7\% less (46,123 USD). Despite these level differences, I do not find evidence for differences in the perceived returns across gender. Nonetheless, there are significant changes in perceived returns when varying the age of the child. More specifically, the warmth dimension becomes less important the older the child is, according to parents' expectations. While for 6 to 9-year-old children a standard deviation increase yields a perceived return of 18.6 percent, it amounts to only 14.7 and 12.7 percent, respectively, for 10 to 12 -year-old and 13 to 16 -year-old children (corresponding t-tests of the difference between coefficients yield $\mathrm{p}$-values of $p=0.060$ and $p=0.003)$. In line with county exposure effects in Chetty and Hendren (2018a), I do not find evidence of perceived critical age effects, during which living in certain neighborhoods is crucial for long-run outcomes. Rather, I find that the interaction of the control dimension of parenting and neighborhoods is perceived to be of particular importance for older children. More specifically, parents associate control to yield an additional 2.9 percentage point return in adverse environments for the oldest age group in my sample. By contrast, there is no such effect for the youngest age group (test of the difference between coefficients: $p=0.042$ ). Thus, parents adapt their return expectations to characteristics of children, such as their age. 
Table 4: Perceived returns by the child's gender and age

\begin{tabular}{|c|c|c|c|c|c|c|c|c|c|}
\hline & \multicolumn{2}{|c|}{$\log \left(y_{i j}\right)$} & \multirow{3}{*}{$\begin{array}{c}\text { p-value } \\
(3) \\
(1)=(2)\end{array}$} & \multicolumn{3}{|c|}{$\log \left(y_{i j}\right)$} & \multicolumn{3}{|c|}{$\mathrm{p}$-values } \\
\hline & $(1)$ & (2) & & (4) & $(5)$ & (6) & (7) & (8) & (9) \\
\hline & Boys & Girls & & $\begin{array}{c}6-9 \\
\text { years }\end{array}$ & $\begin{array}{l}10-12 \\
\text { years }\end{array}$ & $\begin{array}{l}13-16 \\
\text { years }\end{array}$ & $(4)=(5)$ & $(4)=(6)$ & $(5)=(6)$ \\
\hline High warmth & $\begin{array}{l}0.163^{* * *} \\
(0.012)\end{array}$ & $\begin{array}{l}0.142^{* * *} \\
(0.012)\end{array}$ & 0.209 & $\begin{array}{c}0.186^{* * *} \\
(0.014)\end{array}$ & $\begin{array}{l}0.147^{* * *} \\
(0.015)\end{array}$ & $\begin{array}{l}0.127^{* * *} \\
(0.014)\end{array}$ & 0.060 & 0.003 & 0.325 \\
\hline High control & $\begin{array}{l}-0.018^{*} \\
(0.010)\end{array}$ & $\begin{array}{l}-0.003 \\
(0.010)\end{array}$ & 0.266 & $\begin{array}{l}-0.018 \\
(0.013)\end{array}$ & $\begin{array}{l}-0.008 \\
(0.012)\end{array}$ & $\begin{array}{l}-0.005 \\
(0.012)\end{array}$ & 0.557 & 0.434 & 0.832 \\
\hline Good neighborhood & $\begin{array}{l}0.219^{* * *} \\
(0.013)\end{array}$ & $\begin{array}{c}0.233^{* * *} \\
(0.013)\end{array}$ & 0.462 & $\begin{array}{c}0.241^{* * *} \\
(0.017)\end{array}$ & $\begin{array}{l}0.223^{* * *} \\
(0.016)\end{array}$ & $\begin{array}{l}0.214^{* * *} \\
(0.016)\end{array}$ & 0.439 & 0.248 & 0.711 \\
\hline $\begin{array}{l}\text { High warmth } \\
\quad \times \text { High control }\end{array}$ & $\begin{array}{l}0.052^{* * *} \\
(0.013)\end{array}$ & $\begin{array}{l}0.040^{* * *} \\
(0.014)\end{array}$ & 0.547 & $\begin{array}{l}0.037^{* *} \\
(0.017)\end{array}$ & $\begin{array}{l}0.052^{* * *} \\
(0.016)\end{array}$ & $\begin{array}{l}0.050^{* * *} \\
(0.016)\end{array}$ & 0.510 & 0.575 & 0.924 \\
\hline $\begin{array}{l}\text { High warmth } \\
\quad \times \text { Good neighborhood }\end{array}$ & $\begin{array}{l}-0.023^{* *} \\
(0.011)\end{array}$ & $\begin{array}{l}-0.006 \\
(0.011)\end{array}$ & 0.255 & $\begin{array}{l}-0.019 \\
(0.012)\end{array}$ & $\begin{array}{l}-0.019 \\
(0.015)\end{array}$ & $\begin{array}{l}-0.006 \\
(0.013)\end{array}$ & 0.974 & 0.447 & 0.521 \\
\hline $\begin{array}{l}\text { High control } \\
\quad \times \text { Good neighborhood }\end{array}$ & $\begin{array}{l}-0.011 \\
(0.009)\end{array}$ & $\begin{array}{l}-0.020^{* *} \\
(0.008)\end{array}$ & 0.468 & $\begin{array}{c}0.001 \\
(0.010)\end{array}$ & $\begin{array}{l}-0.017 \\
(0.012)\end{array}$ & $\begin{array}{c}-0.029^{* * *} \\
(0.011)\end{array}$ & 0.237 & 0.042 & 0.454 \\
\hline Mean exp. income (in USD) & 49492 & 46123 & & 48373 & 46999 & 47915 & & & \\
\hline Controls for heterogeneity & FE & FE & & FE & FE & FE & & & \\
\hline Observations & 8528 & 8416 & & 5888 & 4896 & 6168 & & & \\
\hline Individuals & 1066 & 1052 & & 736 & 612 & 771 & & & \\
\hline$R^{2}$ & .75 & .71 & & .75 & .74 & .72 & & & \\
\hline
\end{tabular}

Notes: This table presents least squares regressions of log earnings expectations based on equation (1) for different sample splits according to the child's gender (columns 1 and 2) and age group (columns 4-6). Reported p-values stem from t-tests of interaction terms in fully interacted regression models. All specifications include individual fixed effects. Standard errors clustered by respondent in parentheses. *, **, and *** denote significance at the 10 , 5 , and 1 percent level. 


\subsection{Robustness Checks Using Different Sample Restrictions}

In Table 5, I check the robustness of my main findings by restricting the sample in various ways. First, I restrict the sample in column (1) to those respondents who report being one of the main caregivers of the child. Second, after eliciting expectations in the scenarios, I asked how certain parents were about their responses and exclude in column (2) those who report being uncertain or very uncertain. Third, it is possible that respondents either pay little attention and quickly click through the survey or simply perform other activities besides answering the survey. I therefore exclude respondents with the $5 \%$ lowest and highest response times in column (3). Fourth, families actively decide where to move and thus their location decision is endogenous. If they do so due to having different beliefs or if their beliefs are affected by moving to a different neighborhood, this might change their perceptions about returns to parenting and neighborhoods. Column (4) therefore focuses on those respondents that indicated that they moved in the last five years ( $45.5 \%$ of the sample). Finally, I focus on those respondents who have children similar to those in the scenarios and potentially hold more accurate beliefs. Thus, I restrict the sample to those who have children of the same gender (column 4), the same age group (column 5), or both the same gender and age group (column 6) as the children in the scenarios.

As shown in Table 5, neither excluding non-main caregivers, focusing on certain respondents only, or removing respondents with very short or long response times affects the estimates in columns (1) through (3). Those respondents that moved within the last five years perceive the first-order returns to different dimensions of parenting styles as well as to living in a better neighborhood similar to those, who did not move. Yet, they perceive stronger complementarities of the parenting style dimensions (t-test of equality: $p=0.013$ ) and more pronounced substitutability of the control dimension of parenting styles and the neighborhood quality (t-test of equality: $p=0.075$ ). When restricting the sample to those respondents who answer scenarios with hypothetical children sharing their own children's characteristics, the estimates remain robust, although they lose some precision due to smaller samples.

\subsection{Relationship of Returns in the Earnings and Life Satisfaction Domain}

The previous results stem from scenarios in which parents were asked about their expectations for children's earnings at age 30, who are raised with a particular parenting style and in a specific neighborhood. Although monetary returns are appealing for their ease of interpretation, one potential concern with them is that parents may not 
Table 5: Robustness of perceived returns for different samples

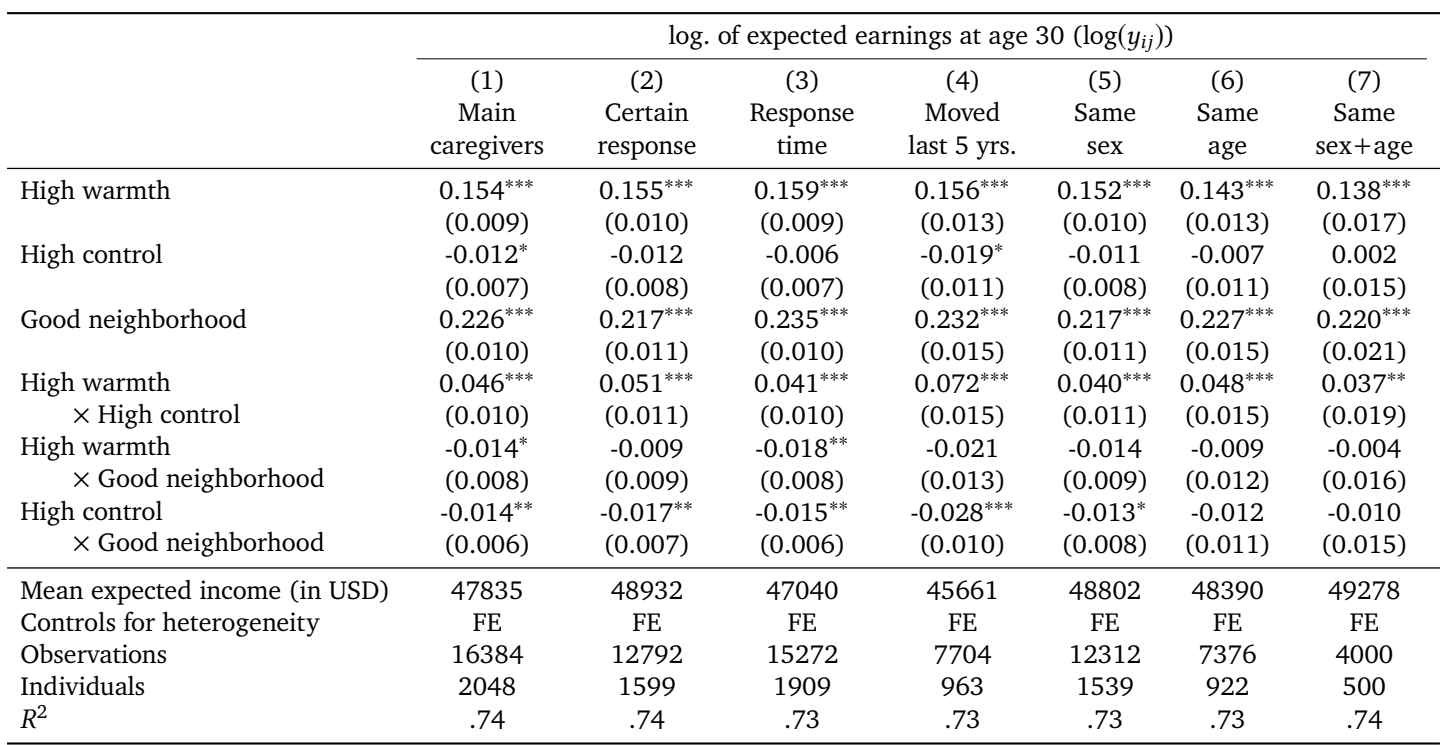

Notes: This table presents least squares regressions of log earnings expectations based on equation (1). Column (1) restricts the sample to respondents who are main caregivers to their children. Column (2) excludes parents who report being uncertain about their responses. Column (3) excludes respondents with the 5\% highest and lowest response times. Column (4) restricts the sample to respondents that indicate that they have moved in the last five years. Columns (5) to (7) restricts the sample to parents whose children and the child in the scenario have the same characteristics in terms of gender (column 5), age group (column 6), and gender, as well as age group (column 7). All specifications include individual fixed effects. Standard errors clustered by respondent in parentheses. *, **, and $* * *$ denote significance at the 10,5 , and 1 percent level.

perceive expected earnings at age 30 as the relevant outcome to evaluate the consequences of different parenting styles. Parents may perceive non-monetary outcomes such as children's well-being or life satisfaction as more important. In order to test whether the results from the monetary domain are comparable to those from other domains, I study a second outcome measure, expected life satisfaction of children at age 30 (measured on a scale from 1 to 100), which parents may have in mind when deciding about the adoption of different parenting styles.

In Figure 2, I examine the relationship between expectations in the earnings and life satisfaction domain. More specifically, the figure displays the distribution of individual-level correlations between expectations across the two domains. For each individual, I calculate the correlation of their expectations for earnings and life satisfaction across the eight scenarios. As depicted, most correlations exceed 0.50 with a mean correlation of $0.63,15$ When analyzing the correlation of individual-

\footnotetext{
${ }^{15}$ Appendix Figure C.1 presents the distribution using rank correlations. These have the advantage of merely requiring an ordinal rather than a cardinal scaling for life satisfaction. The figure reveals that the individual-level correlations are even higher when relying on ranks rather than levels.
} 
Figure 2: Individual-level correlation of earnings and life satisfaction expectations

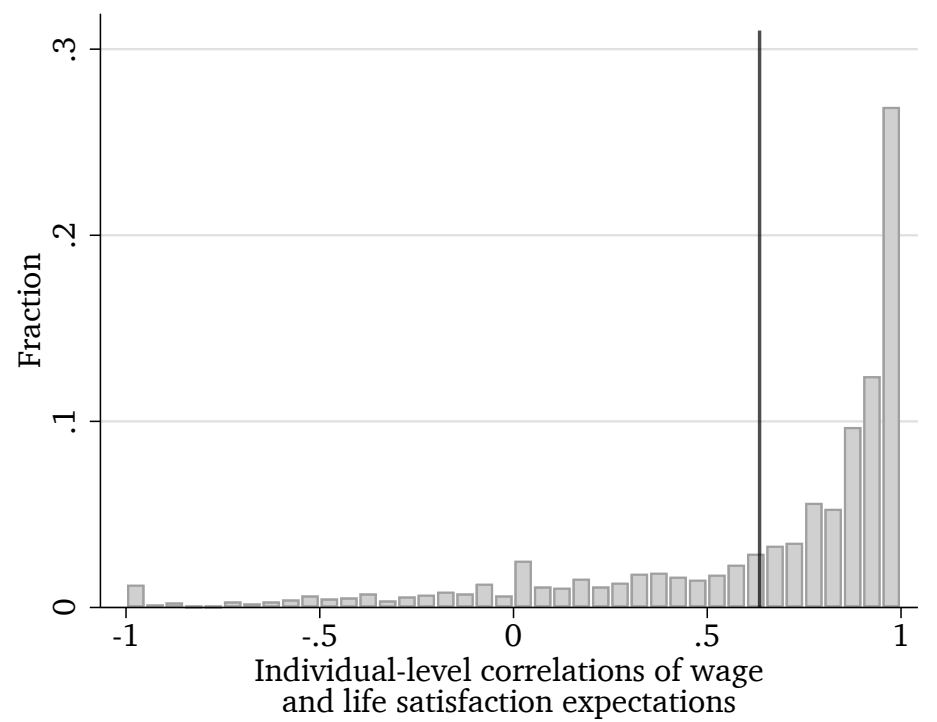

Notes: This figure presents the distribution of individual-level correlations of earnings and life satisfaction expectations. The vertical black line indicates the mean correlation across respondents of 0.63 .

level returns rather than levels, I also find strong correlations between returns in the monetary and returns in the life satisfaction domain, as shown in Appendix Table C.1. Furthermore, Appendix Table C.2 replicates Table 3 by using expected life satisfaction instead of expected earnings as an outcome. The results are both qualitatively and quantitatively similar. This implies that responses in terms of expected earnings are sensible outcomes, capturing returns that not only apply to a monetary domain, but more generally. In the following, I therefore restrict my attention to monetary returns, but will lever the returns in the life satisfaction domain to implement a measurement correction in Section 6 .

\subsection{Accuracy of Beliefs and Perceived Returns}

How accurate are the beliefs parents report in the scenarios? In this section, I briefly discuss their accuracy. As reported in Table 3, the average expected earnings across all eight scenarios is USD 47,810, which is similar to the mean annual earnings in the CPS (approx. USD 46,200 for individuals aged 30 and working). Moreover, similar to findings from the psychology literature (e.g., Chan and Koo, 2011; Dornbusch et al., 1987; Lamborn et al., 1991), parents associate neglecting parenting (low warmth and control) with low outcomes, and authoritative parenting (high warmth and control) with high future outcomes. 
In addition, the associations of sociodemographic characteristics and parental beliefs reported in Table 6 reveal patterns consistent with findings from the literature on subjective wage expectations (e.g., Kaufmann, 2014): Females expect lower earnings, while college educated individuals as well as those with higher household incomes report higher earnings expectations.

Table 6: Parental Belief Production Function

\begin{tabular}{|c|c|c|c|c|c|c|c|c|c|c|}
\hline & \multicolumn{10}{|c|}{ log. of expected earnings at age $30\left(\log \left(y_{i j}\right)\right)$} \\
\hline & (1) & (2) & (3) & (4) & (5) & (6) & (7) & (8) & (9) & (10) \\
\hline Female & $\begin{array}{l}-0.153^{* * *} \\
(0.022)\end{array}$ & & & & & & & & & $\begin{array}{c}-0.075^{* * *} \\
(0.022)\end{array}$ \\
\hline Age & & $\begin{array}{c}0.001 \\
(0.002)\end{array}$ & & & & & & & & $\begin{array}{l}-0.004^{* * *} \\
(0.002)\end{array}$ \\
\hline White & & & $\begin{array}{c}0.015 \\
(0.027)\end{array}$ & & & & & & & $\begin{array}{l}-0.030 \\
(0.025)\end{array}$ \\
\hline College degree & & & & $\begin{array}{c}0.246^{* * *} \\
(0.021)\end{array}$ & & & & & & $\begin{array}{l}0.097^{* * * *} \\
(0.022)\end{array}$ \\
\hline Employed & & & & & $\begin{array}{c}0.127^{* * * *} \\
(0.023)\end{array}$ & & & & & $\begin{array}{c}-0.052^{* * *} \\
(0.024)\end{array}$ \\
\hline $\log$ (Household income) & & & & & & $\begin{array}{c}0.218^{* * *} \\
(0.015)\end{array}$ & & & & $\begin{array}{c}0.196^{* * * *} \\
(0.019)\end{array}$ \\
\hline Single parent & & & & & & & $\begin{array}{c}-0.142^{* * *} \\
(0.025)\end{array}$ & & & $\begin{array}{c}0.021 \\
(0.026)\end{array}$ \\
\hline Number of children & & & & & & & & $\begin{array}{c}-0.005 \\
(0.010)\end{array}$ & & $\begin{array}{c}0.002 \\
(0.010)\end{array}$ \\
\hline Share of female children & & & & & & & & & $\begin{array}{c}0.007 \\
(0.027)\end{array}$ & $\begin{array}{c}0.014 \\
(0.025)\end{array}$ \\
\hline Mean exp. income (in USD) & 47810 & 47810 & 47810 & 47810 & 47810 & 47810 & 47810 & 47810 & 47810 & 47810 \\
\hline Observations & 16952 & 16952 & 16952 & 16952 & 16952 & 16952 & 16952 & 16952 & 16952 & 16952 \\
\hline Individuals & 2119 & 2119 & 2119 & 2119 & 2119 & 2119 & 2119 & 2119 & 2119 & 2119 \\
\hline$R^{2}$ & .016 & .00012 & .00011 & .043 & .0091 & .081 & .0078 & .000075 & .000021 & .092 \\
\hline
\end{tabular}

Notes: This table presents least squares regressions of log earnings expectations on individual characteristics. Standard errors clustered by respondent in parentheses. *, **, and *** denote significance at the 10,5 , and 1 percent level.

In order to compare the perceived returns to actual returns, I conduct two comparisons. $\sqrt{16}$ First, I compare perceived returns from my sample to average marginal effects of intensive parenting styles from Falk et al. (forthcoming). They estimate how children's skills develop as a function of intensive parenting styles. While they do not consider different dimensions of parenting styles (i.e., warmth and control), they construct a latent factor based on similar survey items. Falk et al. find marginal effects ranging from 0.313 to 0.424 , which are somewhat higher than the combined effects of warmth and control reported in Table 3.17

\footnotetext{
${ }^{16}$ Boneva and Rauh (2018) show in a related setting, in which they analyze the perceived returns to parental investments at different ages, that hypothetical scenario approaches as adopted in this paper yields perceived returns similar to actual returns.

${ }^{17}$ Note that the outcomes I am interested in here are long-term outcomes at age 30. In contrast, Falk et al. (forthcoming) are interested in the development of skills during childhood. Since these skills translate only imperfectly into earnings, these higher returns are consistent with the perceived returns reported here.
} 
Second, I exploit the fact that respondents were asked to state their beliefs for children of average American families. I draw on data from the National Longitudinal Survey of Youth 1997 (NLSY97), in which children aged 12-17 in 1997 evaluate both their mothers' and their fathers' parenting style. Regressing the log earnings of respondents in 2013, when they were on average 30 years old, on indicators for warmth and control, as well as their interaction (see Appendix Table G.1) reveals returns similar to the average perceived returns in my sample: The return to mother's warmth and control is .104 and .020, respectively, while the coefficient on the interaction is .026 , indicating returns both quantitatively and qualitatively consistent with those in Table 3. Using their fathers' parenting styles yields similar results 18 Taken together, the perceived returns in my dataset seem to be consistent with actual returns from other settings.

\section{Heterogeneity in Individual-level Returns}

The previous section documented perceived returns to different parenting styles and neighborhoods. Yet, these returns depict only average patterns. In the following, I want to characterize the heterogeneity in perceived returns in more detail. To do so, I additionally estimate equation (1) individual by individual to recover each parent's perceived returns, and subsequently link these to individual determinants 19

Figure 3 and Table 7 present the distributions of returns to the three dimensions warmth, control, and neighborhood. Several findings emerge. First, there is large heterogeneity in perceived returns. The majority of respondents expect positive returns to all three dimensions, with less than $20 \%$ of the sample expecting negative returns to warmth and neighborhoods. This number amounts to approximately $40 \%$ for control. Second, there is a sizable fraction of parents who do not expect parenting styles or neighborhoods to matter, with shares of $14 \%$ for neighborhoods to $32 \%$ in the control dimension. Third, correlations of returns across the three dimensions are positive, though not perfect, indicating that the different dimensions are related, but

\footnotetext{
${ }^{18}$ Two qualifications are in order. First, parenting styles in the NLSY97 are elicited using two questions asking children whether their mother (father) is supportive and strict to capture the warmth and control dimension. Second, note that these estimates are correlations and should not be interpreted as causal. Yet, respondents in the survey were asked to state their beliefs over the outcomes of children of average American families. Hence, looking at these basic regressions is informative, despite not accounting for measurement error, the endogeneity of parenting styles, and other confounding factors. In addition to monetary returns, Appendix Table G.1 also presents results from the NLSY on children's high school GPA with similar patterns: The warmth dimension of parenting has large positive returns, while control has smaller, albeit positive returns.

${ }^{19}$ To avoid results being driven by outliers, I winsorize perceived returns at the $1 \%$ and $99 \%$ level.
} 
Figure 3: Distribution of individual-level perceived returns

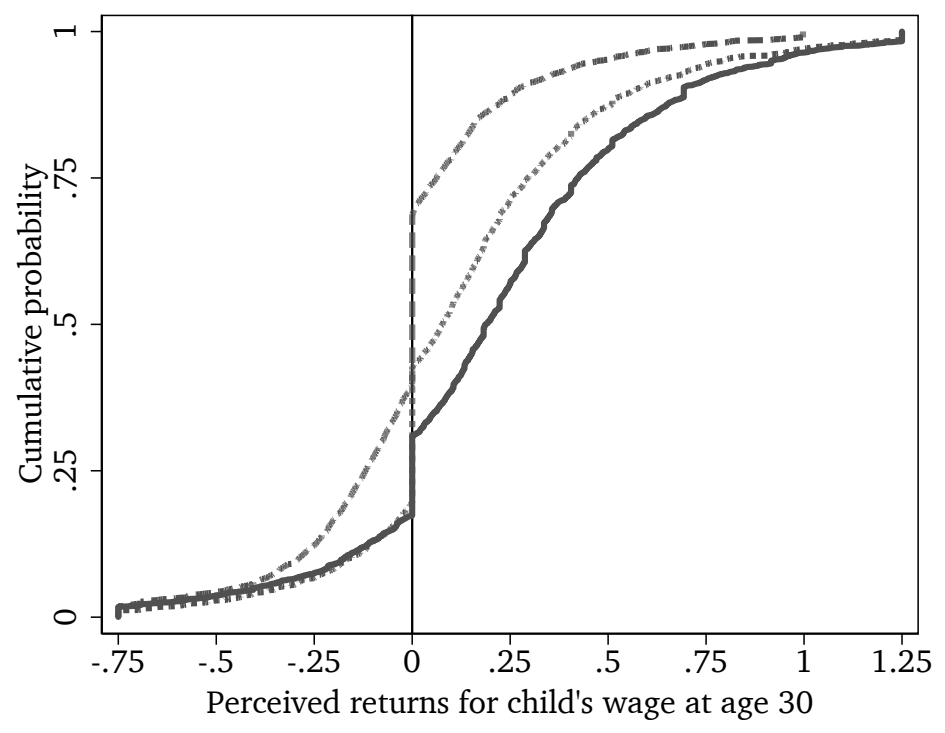

Notes: This figure presents the distributions of individual-level perceived returns based on equation (1) for the dimensions warmth ( $R_{\text {warmth }, i}$; dotted), control $\left(R_{\text {control }, i}\right.$; dashed $)$, and neighborhood $\left(R_{\text {neighb., } i}\right.$; solid).

capture distinct concepts. 20 Taken together, most parents expect that parenting can pay off for children's long-term outcomes.

Table 7: Correlations of individual-level perceived returns

\begin{tabular}{lccc}
\hline & $R_{\text {warmth }, i}$ & $R_{\text {control }, i}$ & $R_{\text {neighb. }, i}$ \\
\hline$R_{\text {warmth }, i}$ & 1.000 & & \\
$R_{\text {control }, i}$ & $0.254^{* * *}$ & 1.000 & \\
$R_{\text {neighb. } i}$ & $0.290^{* * *}$ & $0.255^{* * *}$ & 1.000 \\
\hline
\end{tabular}

Notes: This table presents correlations of individual-level returns across the three dimensions warmth $\left(R_{\text {warmth }, i}\right)$, control $\left(R_{\text {control, } i}\right)$ and neighborhood $\left(R_{\text {neighb }, i}\right) . *, * *$, and $* * *$ denote significance at the 10,5 , and 1 percent level.

To what extent is the heterogeneity in the distribution of perceived returns systematic? One point of departure is to investigate potential differences in the perceived returns by parental gender. In particular, there is evidence that mothers spend about twice as much time on child-rearing activities as fathers (Guryan, Hurst, and Kearney, 2008) ${ }^{21}$ I therefore analyze differences in the distribution of perceived returns

\footnotetext{
${ }^{20}$ Moreover, zero perceived returns are highly correlated across the different dimensions; see Appendix Table D.1.

${ }^{21}$ Moreover, data from the National Longitudinal Survey of Youth 1997 also reveals differences by parental gender. In particular, mothers are approximately 5.7 and 1.8 percentage points more likely
} 
to the three dimensions warmth, control, and neighborhood between fathers (blue, dashed lines) and mothers (red, solid lines). Figures 4a 4c reveal significant gender differences in parental perceptions: Mothers expect larger returns than fathers in the warmth (t-test of equality of means: $p<0.001$; Kolmogorov-Smirnov tests of equality of distributions: $p<0.001$ ) and neighborhood dimensions (t-tests: $p<0.001$, KStest: $p=0.004$ ), while there are no significant differences in the control dimension (t-test: $p=0.291$, KS-test: $p=0.150$ ). Moreover, mothers' higher perceived returns seem to be relatively uniform across the distribution.

Figure 4: Distribution of individual-level perceived returns by parental gender

(a) Warmth $\left(R_{\text {warmth, } i}\right)$

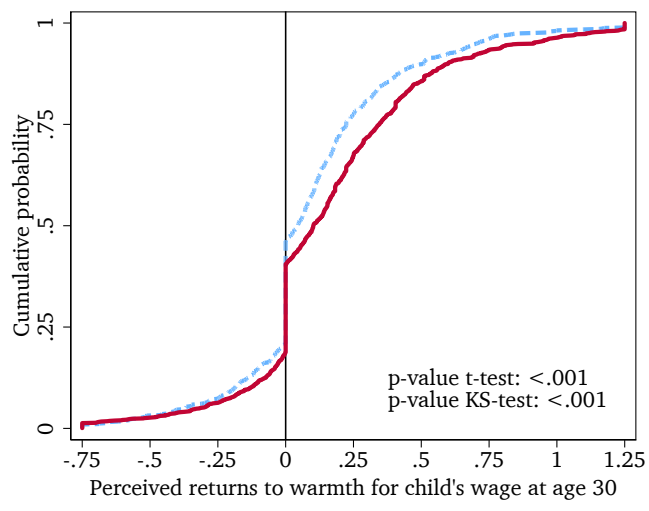

(b) Control $\left(R_{\text {control, } i}\right)$

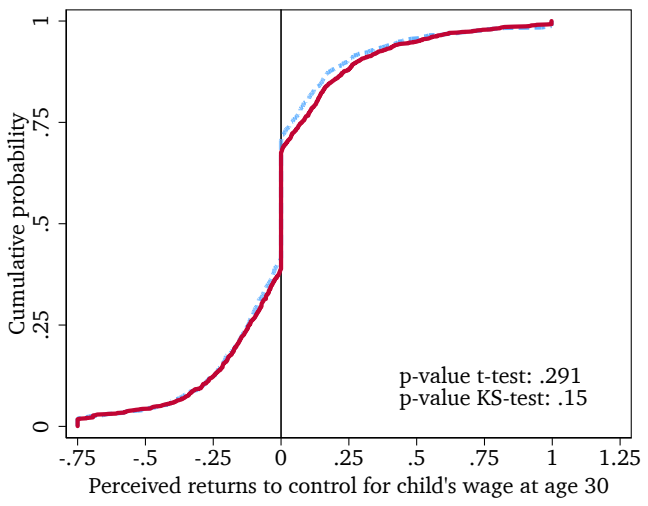

(c) Neighborhood $\left(R_{\text {neighb., } i}\right)$

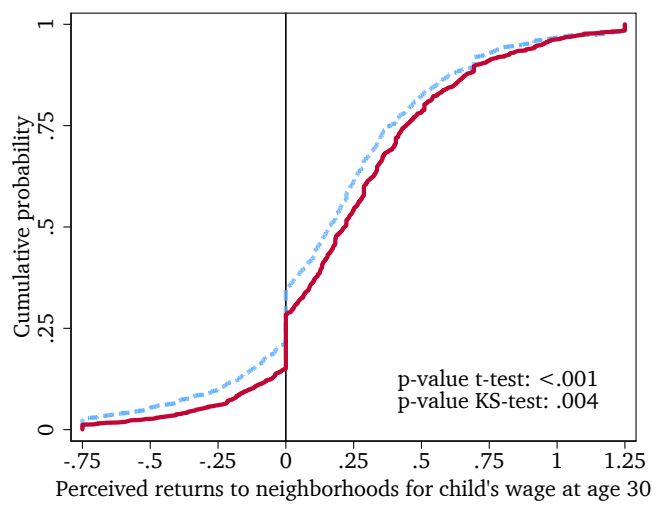

Notes: These figures present the distributions of individual-level perceived returns based on equation (1) for the dimensions warmth $\left(R_{\text {warmth }, i}\right.$; Figure $\left.4 \mathrm{a}\right)$, control $\left(R_{\text {control, } i}\right.$; Figure $\left.4 \mathrm{~b}\right)$ and neighborhood $\left(R_{\text {neighb., } i}\right.$; Figure $\left.4 c\right)$ for mothers (solid, red) and fathers (dashed, blue) separately.

In the following, I analyze whether perceived returns are related to other parental characteristics besides gender. More specifically, based on equation (2), I analyze how perceived returns, i.e., differences between scenarios, vary with observable character-

to adopt parenting styles featuring high levels of warmth and control, respectively (see Appendix Table G.2). 
istics and parenting values. Columns (2)-(4) of Table 8 investigate whether the size of the perceived returns are related to parents' characteristics. Interestingly, apart from gender differences in the warmth $(+6.2 \%)$ and neighborhood dimensions $(+6.3 \%)$ as shown in Figure 4, almost no other characteristics seem to be systematically associated with perceived returns. In particular, I cannot reject the hypothesis that all other sociodemographic coefficients jointly equal zero in each of the three specifications regarding warmth (F-test: $p=0.108$ ), control (F-test: $p=0.935$ ), and neighborhoods (F-test: $p=0.300$ ) in columns (1)-(3), respectively.

Table 8: Determinants of individual-level perceived returns

\begin{tabular}{lccc}
\hline & \multicolumn{3}{c}{ Perceived Returns } \\
\cline { 2 - 4 } & $(1)$ & $(2)$ & $(3)$ \\
& $R_{\text {warmth, } i}$ & $R_{\text {control, } i}$ & $R_{\text {neighb., }}$ \\
\hline Female & $0.062^{* * *}$ & 0.015 & $0.063^{* * *}$ \\
Age & $(0.017)$ & $(0.014)$ & $(0.020)$ \\
& -0.000 & -0.000 & $0.003^{* * *}$ \\
White & $(0.001)$ & $(0.001)$ & $(0.001)$ \\
College degree & $0.047^{* *}$ & 0.016 & 0.004 \\
& $(0.019)$ & $(0.015)$ & $(0.022)$ \\
Employed & -0.005 & -0.007 & -0.004 \\
log(Household income) & $(0.019)$ & $(0.015)$ & $(0.020)$ \\
Single parent & -0.021 & -0.003 & -0.016 \\
& $(0.020)$ & $(0.015)$ & $(0.023)$ \\
Number of children & 0.019 & 0.006 & -0.003 \\
Share of female children & $0.014)$ & $(0.012)$ & $(0.016)$ \\
& $0.047^{*}$ & -0.005 & 0.019 \\
& $(0.025)$ & $(0.020)$ & $(0.027)$ \\
Average return & 0.009 & -0.005 & 0.002 \\
Observations & $(0.008)$ & $(0.006)$ & $(0.009)$ \\
$R^{2}$ & $(0.021)$ & $(0.017)$ & $(0.022)$ \\
\hline
\end{tabular}

Notes: This table presents regressions of parental beliefs about children's expected log-earnings in column (1) or individual-level perceived returns to warmth $\left(R_{\text {warmth }, i}\right.$; columns 1 and 4$)$, control ( $R_{\text {control, }, i}$; columns 2 and 5 ), as well as neighborhood $\left(R_{\text {neighb., } i}\right.$; columns 3 and 6 ) on sociodemographic characteristics according to equation (2). Individual-level perceived returns are estimated based on equation (1) for each individual separately. Clustered standard errors by respondent in column (1) and robust standard errors in columns (2)-(4) in parentheses. *, **, and *** denote significance at the 10,5 , and 1 percent level. 
The absence of a relationship is surprising, given that Boneva and Rauh (2018) find systematic associations for some characteristics, but it is in line with other studies (e.g., Attanasio, Boneva, and Rauh, 2019), which do not find associations either.22 Thus, there are sizable differences in both the level (as shown in Table 6) beliefs as well as perceived returns by parental gender, but no differences in perceived returns along variables capturing differences in socioeconomic status. Moreover, as I will show in Section 6, these perceived returns are highly predictive for actual parenting styles. The absence of associations between sociodemographics and perceived returns therefore indicates that they capture an important aspect of parental decision-making that is distinct from standard individual characteristics and constraints.

Table 9: Determinants of individual-level perceived returns II

\begin{tabular}{lccc}
\hline & \multicolumn{3}{c}{ Perceived Returns } \\
\cline { 2 - 4 } & $(1)$ & $(2)$ & $(3)$ \\
& $R_{\text {warmth, } i}$ & $R_{\text {control, } i}$ & $R_{\text {neighb., }}$ \\
\hline Altruism towards child (std.) & $0.018^{* *}$ & -0.005 & $0.028^{* * *}$ \\
& $(0.007)$ & $(0.006)$ & $(0.009)$ \\
Paternalism towards child (std.) & 0.001 & $0.013^{*}$ & 0.002 \\
& $(0.008)$ & $(0.007)$ & $(0.009)$ \\
Malleability of skills (std.) & $0.030^{* * *}$ & $0.011^{*}$ & $0.050^{* * *}$ \\
& $(0.008)$ & $(0.007)$ & $(0.009)$ \\
\hline Average return & .15 & -.01 & .23 \\
Sociodemographic controls & Yes & Yes & Yes \\
Individuals & 2109 & 2109 & 2109 \\
$R^{2}$ & .023 & .0053 & .028 \\
\hline
\end{tabular}

Notes: This table presents regressions of individual-level perceived returns to warmth $\left(R_{\mathrm{warmth}, i}\right.$; columns 1 and 4 ), control ( $R_{\text {control, } i}$; columns 2 and 5 ) as well as neighborhood ( $R_{\text {neighb., } i}$; columns 3 and 6) on parenting values and controls for respondent's age and gender, as well as indicators for being white, having a college degree, being employed, and being a single parent, log-household income, number of children in the household, and the share of children being female according to equation (2) and as shown in Table 8 . Individual-level perceived returns are estimated based on equation (1) for each individual separately. Robust standard errors in parentheses. *, **, and *** denote significance at the 10,5 , and 1 percent level.

In addition to demographic characteristics, the survey also elicited respondents' parenting values. These variables measure parents altruism and paternalism towards their own children, as well as their belief in the malleability of skills. Table 9 reveals some interesting patterns: All three perceived return measures are significantly re-

\footnotetext{
${ }^{22}$ One explanation for these differences could be that Boneva and Rauh (2018) and Attanasio, Boneva, and Rauh (2019) study families in the United Kingdom, with only the latter study employing a representative sample of parents similar to the present paper.
} 
lated to parents' beliefs about the malleability of skills, similar to Attanasio, Boneva, and Rauh (2019) and Boneva and Rauh (2018). In particular, those parents who believe that skills are malleable perceive returns to be higher. In other words, those parents who do not share this belief react less to differences across scenarios. Moreover, returns in the warmth and neighborhood dimensions are related to the parents' altruism towards their children, whereas returns in the control dimension are associated with parental paternalism. This is consistent with theoretical results by Doepke and Zilibotti (2017), who show that sufficiently paternalistic parents adopt parenting styles with more control, i.e., authoritarian or authoritative parenting styles in which parents exert effort to mold their children's preferences, ${ }^{23}$ Parents' altruism and paternalism are two key parameters in their model that lead to different parenting styles.

To test for the robustness of these results, I conduct two robustness checks presented in Appendix D. First, as shown in Figure 3, a sizable fraction of respondents expect zero returns in some dimensions and expecting zero returns is correlated across dimensions (cf. Appendix Table D.1). In Appendix Table D.2, I therefore exclude those respondents that report zero returns to parenting or living in a good neighborhood. The results are qualitatively as well as quantitatively similar. Second, I present a different approach to analyze the determinants of perceived returns. There, I adopt an IV strategy similar to equation (3), which levers perceived returns in both the earnings as well as the life satisfaction domain, and tries to predict sociodemographic characteristics. If the lack of significant determinants in Table 8 is just due to a high degree of measurement error and thus lower statistical power, using the returns as explanatory variables and applying a measurement correction should partly correct for measurement error. Yet, results in Appendix Table D.3 confirm the previous patterns: Females expect larger returns to warmth as well as neighborhoods, and parenting values show the same associations as reported above, but other characteristics do not seem to be strongly related to perceived returns.

\section{Relevance of Perceived Returns for Actual Behavior}

To what extent do perceived returns, as described above, map into actual parental decision-making? In this section, I study their relevance by analyzing the association of perceived returns with parents' actual parenting behavior. Hence, I focus on the predictive power of returns for actual parenting styles. In the previous sections, I

\footnotetext{
${ }^{23}$ Appendix Table D.2 shows that respondents with more children, females, paternalistic parents, and those who believe that skills are malleable are less likely to expect zero returns to parenting. Accounting for respondents reporting zero returns does not change the results reported in this section.
} 
have shown that perceived returns capture some aspects of parenting that are not related to sociodemographic characteristics, but at the same time they exhibit patterns consistent with actual returns. If perceived returns translated into actual parental decision-making, their relevance would be even higher in light of the lacking relationship to sociodemographic characteristics.

Table 10 examines the relevance of perceived returns for actual parenting styles. Specifically, I relate (standardize) perceived returns in each of the two domains to parenting styles measured by established instruments of Perris et al. (1980) (warmth) and Schwarz et al. (1997) (control), and adopt the IV strategy outlined in equation (3) of Section 3. Panel (A) focuses on the warmth dimension by relating estimated returns in the earnings (column 1) and life satisfaction domain (column 2) to warm parenting. The estimates reveal that returns in both domains are significantly related to parenting behavior. An increase of one standard deviation in perceived returns is associated with a 0.043 standard deviation increase in the warmth dimension of parenting styles. Although these individual-level returns are subject to measurement error, as they are estimated only on eight observations per respondent, they capture a similar underlying factor. In the remaining columns, I therefore instrument perceived returns in the earnings (life satisfaction) domain with perceived returns in the life satisfaction (earnings) domain to reduce measurement error and to recover the a more general notion of perceived returns that is not restricted to a particular domain. Doing so, I find even larger associations of 0.084-0.088 standard deviations for an increase of one standard deviation in perceived returns that even hold when simultaneously controlling for perceived returns in the control dimension.

A similar picture arises when analyzing the role of perceived returns to control for the control dimension of parenting styles. While the perceived returns in the monetary domain are positive but insignificant ( $p=0.161$ ), perceived returns measured in the life satisfaction domain and specifications accounting for measurement error reveal significant associations even if simultanously controlling for return to warmth.

Finally, Appendix F presents additional results linking perceived returns to neighborhoods to actual neighborhood characteristics. The results show that although there is only limited evidence for perceived returns to predict subjective neighborhoods assessments or economic conditions, perceived returns are strongly related to living in areas less segregation. In sum, the results from this section suggest that parents do not only adapt their expectations when faced with scenarios of varying parenting styles, but the corresponding returns are also relevant for their actual parenting behavior. 
Table 10: Relevance of perceived returns for actual parenting styles

\begin{tabular}{|c|c|c|c|c|c|c|c|c|}
\hline & \multicolumn{4}{|c|}{ (A) Warmth dimension of parenting styles } & \multicolumn{4}{|c|}{ (B) Control dimension of parenting styles } \\
\hline & (1) & (2) & (3) & (4) & (5) & (6) & (7) & (8) \\
\hline & $\begin{array}{c}\text { Expected } \\
\text { earnings }\end{array}$ & $\begin{array}{l}\text { Expected } \\
\text { Life Satis. }\end{array}$ & IV & IV & $\begin{array}{l}\text { Expected } \\
\text { earnings }\end{array}$ & $\begin{array}{l}\text { Expected } \\
\text { Life Satis. }\end{array}$ & IV & IV \\
\hline$R_{\text {warmth }, i}$ (std.) & $\begin{array}{c}0.043^{* * *} \\
(0.016)\end{array}$ & $\begin{array}{l}0.044^{* *} \\
(0.019)\end{array}$ & $\begin{array}{c}0.084^{* * *} \\
(0.025)\end{array}$ & $\begin{array}{c}0.088^{* * *} \\
(0.025)\end{array}$ & & & & $\begin{array}{l}-0.039 \\
(0.025)\end{array}$ \\
\hline$R_{\text {control, }, i}$ (std.) & & & & $\begin{array}{c}-0.021 \\
(0.030)\end{array}$ & $\begin{array}{c}0.026 \\
(0.018)\end{array}$ & $\begin{array}{c}0.055^{* * *} \\
(0.017)\end{array}$ & $\begin{array}{c}0.092^{* * *} \\
(0.029)\end{array}$ & $\begin{array}{l}0.102^{* * *} \\
(0.029)\end{array}$ \\
\hline Controls & Yes & Yes & Yes & Yes & Yes & Yes & Yes & Yes \\
\hline Observations & 2119 & 2119 & 4238 & 4238 & 2119 & 2119 & 4238 & 4238 \\
\hline Individuals & 2119 & 2119 & 2119 & 2119 & 2119 & 2119 & 2119 & 2119 \\
\hline$R^{2}$ & .046 & .046 & .044 & .044 & .036 & .04 & .045 & .045 \\
\hline
\end{tabular}

Notes: This table examines the relevance of perceived returns for actual parenting styles by estimating equation (3). Panel (A) presents results for the warmth dimension using (standardized) perceived returns to warmth, while Panel (B) presents corresponding results in the control dimension. Columns (1) and (5) use returns in the earnings domain, while columns (2) and (6) employ returns in the life satisfaction domain. Columns (3) and (7) implement the IV strategy based on equation (3) to correct for measurement error in perceived returns using the two return measures as instruments for each other. Columns (4) and (8) additionally include (instrumented) perceived returns to control and warmth, respectively. All specifications include respondent's age and gender, as well as indicators for being white, having a college degree, being employed, and being a single parent, log-household income, number of children in the household, and the share of children being female as control variables as in Table 3 . Bootstrapped standard errors from 1,000 repetitions in parentheses. *, **, and *** denote significance at the $10 \%, 5 \%$, and $1 \%$ level.

\section{Conclusion}

While parents are crucial for the development of children, parenting itself remains a "mystifying subject" (Bornstein, 2002). In order to better understand how parents decide to raise their children, I focus on parents' beliefs constituting an inherent part of their decision-making process. I conduct a survey that is among the first to investigate parental beliefs of a representative sample of parents. In the main part of the survey, I elicit beliefs using a hypothetical scenario approach that varies two factors with importance for the development of children and, hence, their long-term outcomes: first, the parenting style defined by the levels of warmth and control parents employ in raising their children, and, second, the quality of the neighborhood in which a family lives. This allows me to infer parents' perceived returns to these different dimensions and sheds light on their perceived substitutability or complementarity.

My analysis shows that parents expect large returns to the warmth dimension of parenting styles and to living in good neighborhoods. Parenting styles with high levels of control are only associated with positive returns if they are paired with warmth suggesting that these two dimensions are perceived as complements. Moreover, I 
show that parents expect parenting and neighborhoods to interact. In particular, they believe that parenting can partly compensate for living in deprived neighborhoods.

When studying perceived returns on the individual level, my estimates reveal profound gender differences: mothers expect significantly larger returns than fathers in the warmth and neighborhood dimension, while parental perceptions are similar for the control dimension. Perhaps surprisingly, other sociodemographic characteristics of these perceived returns are not related to parental beliefs. The absence of a socioeconomic gradient in perceived returns suggests that they are an unlikely candidate to explain socioeconomic differences in parenting behavior. Rather, the interaction between parenting and neighborhoods could provide an explanation for persistent differences in parenting across sociodemographic groups which might increase as neighborhoods become more homogeneous over time (Putnam, 2016). To the extent that some form of "optimal parenting" exists, my results suggest that the optimal parenting behavior may be environment-specific.

Importantly, the perceived returns I recover are relevant for actual parenting behavior as they predict parents actual parenting styles. Hence, they capture an important determinant of parental decision-making, but cannot be proxied by standard socioeconomic variables. This highlights the value of studying beliefs to understand parental decision-making processes.

The results of this paper open at least two avenues for further research. First, since the returns to parental investments hinge on the parenting style (Cunha, 2015), it would be interesting to analyze the relationship between the quality margin of parenting considered in this paper and the quantity margin as in the previous literature (Attanasio, Boneva, and Rauh, 2019; Bhalotra et al., 2020; Boneva and Rauh, 2018). Second, as beliefs about returns to parenting depends on the quality of neighborhoods, this calls for a deeper understanding of the human capital formation process and the relationship between parenting and a family's environment more generally (as, e.g., in Agostinelli et al., 2020). 


\section{References}

Agostinelli, Francesco (2018). “Investing in Children's Skills: An Equilibrium Analysis of Social Interactions and Parental Investments". Working Paper.

Agostinelli, Francesco, Matthias Doepke, Giuseppe Sorrenti, and Fabrizio Zilibotti (2020). "It takes a Village: The Economics of Parenting with Neighborhood and Peer Effects". Working Paper.

Arcidiacono, Peter, V. Joseph Hotz, and Songman Kang (2012). "Modeling college major choices using elicited measures of expectations and counterfactuals". In: Journal of Econometrics 166.1, pp. 3-16.

Attanasio, Orazio P. (2015). "The Determinants of Human Capital Formation during the Early Years of Life: Theory, Measurement, and Policies". In: Journal of the European Economic Association 13.6, pp. 949-997.

Attanasio, Orazio P., Teodora Boneva, and Christopher Rauh (2019). "Parental Beliefs about Returns to Different Types of Investments in School Children". Working Paper.

Attanasio, Orazio P. and Katja M. Kaufmann (2014). "Education choices and returns to schooling: Mothers' and youths' subjective expectations and their role by gender". In: Journal of Development Economics 109, pp. 203-216.

Baumrind, Diana (1967). "Child Care Practices Anteceding Three Patterns of Preschool Behavior”. In: Genetic Psychology Monographs 75 (1), pp. 43-88.

Beffy, Magali, Denis Fougère, and Arnaud Maurel (2012). "Choosing the Field of Study in Postsecondary Education: Do Expected Earnings Matter?" In: Review of Economics and Statistics 94.1, pp. 334-347.

Bhalotra, Sonia, Adeline Delavande, Paulino Font, and Joanna Maselko (2020). "Maternal Investments in Children: The Role of Expected Efforts and Returns". Working Paper.

Boneva, Teodora and Christopher Rauh (2018). "Parental Beliefs about Returns to Educational Investments-The Later the Better?" In: Journal of the European Economic Association 16.6, pp. 1669-1711.

Bornstein, Marc H. (2002). "Preface". In: Handbook of Parenting. Practical Issues in Parenting. Ed. by M. H. Bornstein. Vol. 5. Lawrence Erlbaum Associates, pp. xixiv.

Brenøe, Anne Ardila and Thomas Epper (2019). "Parenting Values Moderate the Intergenerational Transmission of Time Preferences". Working Paper.

Chan, Tak Wing and Anita Koo (2011). "Parenting Style and Youth Outcomes in the UK". In: European Sociological Review 27.3, pp. 385-399.

Chetty, Raj, John N. Friedman, Nathaniel Hendren, Maggie R. Jones, and Sonya R. Porter (2018). "The Opportunity Atlas: Mapping the Childhood Roots of Social Mobility". Working Paper. 
Chetty, Raj and Nathaniel Hendren (2018a). "The Impacts of Neighborhoods on Intergenerational Mobility I: Childhood Exposure Effects". In: Quarterly Journal of Economics 133.3, pp. 1107-1162.

- (2018b). "The Impacts of Neighborhoods on Intergenerational Mobility II: CountyLevel Estimates". In: Quarterly Journal of Economics 133.3, pp. 1163-1228.

Cobb-Clark, Deborah A., Nicolás Salamanca, and Anna Zhu (2019). "Parenting style as an investment in human development". In: Journal of Population Economics 32.4, pp. 1315-1352.

Cosconati, Marco (2012). "Parenting Style and the Development of Human Capital in Children". Working Paper.

Cuellar, Jessica, Deborah J. Jones, and Emma Sterrett (2015). "Examining Parenting in the Neighborhood Context: A Review". In: Journal of Child and Family Studies 24.1, pp. 195-219.

Cunha, Flavio (2015). "Subjective Rationality, Parenting Styles, and Investments in Children". In: National symposium on family issues. Diverging Destinies: Families in an Era of Increasing Inequality. Ed. by P. Amato, A. Booth, S. McHale, and J. Van Hook. Vol. 5. Springer. Chap. 6, pp. 83-94.

Cunha, Flavio, Irma Elo, and Jennifer Culhane (2013). "Eliciting Maternal Subjective Expectations about the Technology of Cognitive Skill Formation". Working Paper.

Cunha, Flavio and James J. Heckman (2007). "The Technology of Skill Formation". In: American Economic Review 97.2, pp. 31-47.

Cunha, Flavio, James J. Heckman, and Susanne M. Schennach (2010). "Estimating the Technology of Cognitive and Noncognitive Skill Formation". In: Econometrica 78.3, pp. 883-931.

Del Bono, Emilia, Marco Francesconi, Yvonne Kelly, and Amanda Sacker (2016). "Early Maternal Time Investment and Early Child Outcomes". In: Economic Journal 126.596, F96-F135.

Deutscher, Nathan (forthcoming). "Place, Peers, and the Teenage Years: Long-run Neighborhood Effects in Australia". In: American Economic Journal: Applied Economics.

Doepke, Matthias, Giuseppe Sorrenti, and Fabrizio Zilibotti (2019). "The Economics of Parenting". In: Annual Review of Economics 11.1, pp. 55-84.

Doepke, Matthias and Fabrizio Zilibotti (2017). "Parenting With Style: Altruism and Paternalism in Intergenerational Preference Transmission". In: Econometrica 85.5, pp. 1331-1371.

Dominitz, Jeff and Charles F. Manski (1996). "Eliciting Student Expectations of the Returns to Schooling". In: Journal of Human Resources 31.1, pp. 1-26.

Dooley, Martin and Jennifer Stewart (2007). "Family income, parenting styles and child behavioural-emotional outcomes". In: Health Economics 16.2, pp. 145-162. 
Dornbusch, Sanford M., Philip L. Ritter, P. Herbert Leiderman, Donald F. Roberts, and Michael J. Fraleigh (1987). "The Relation of Parenting Style to Adolescent School Performance". In: Child Development 58.5, pp. 1244-1257.

Ermisch, John (2008). "Origins of Social Immobility and Inequality: Parenting and Early Child Development”. In: National Institute Economic Review 205.1, pp. 6271.

Falk, Armin, Fabian Kosse, Pia Pinger, Hannah Schildberg-Hörisch, and Thomas Deckers (forthcoming). "Socio-Economic Status and Inequalities in Children's IQ and Economic Preferences". In: Journal of Political Economy.

Fiorini, Mario and Michael P. Keane (2014). "How the Allocation of Children's Time Affects Cognitive and Noncognitive Development". In: Journal of Labor Economics 32.4, pp. 787-836.

Francesconi, Marco and James J. Heckman (2016). "Child Development and Parental Investment: Introduction”. In: Economic Journal 126.596, F1-F27.

Gillen, Ben, Eric Snowberg, and Leeat Yariv (2019). "Experimenting with Measurement Error: Techniques with Applications to the Caltech Cohort Study". In: Journal of Political Economy 124.4, pp. 1826-1863.

Giustinelli, Pamela (2016). "Group Decision Making with Uncertain Outcomes: Unpacking Child-Parent Choice of the High School Track". In: International Economic Review 57.2, pp. 573-602.

Guryan, Jonathan, Erik Hurst, and Melissa Kearney (2008). "Parental Education and Parental Time with Children”. In: Journal of Economic Perspectives 22.3, pp. 23-46.

Han, Joal Kaiyuan (2019). "Parental Involvement and Neighborhood Quality: Evidence from Public Housing Demolitions in Chicago". Working Paper.

Hastings, Justine S., Christopher A. Neilson, Anely Ramirez, and Seth D. Zimmerman (2016). "(Un)informed college and major choice: Evidence from linked survey and administrative data". In: Economics of Education Review 51, pp. 136-151.

Jensen, Robert (2010). "The (Perceived) Returns to Education and the Demand for Schooling". In: Quarterly Journal of Economics 125.2, pp. 515-548.

Kalil, Ariel (2015). "Inequality Begins at Home: The Role of Parenting in the Diverging Destinies of Rich and Poor Children". In: National symposium on family issues. Diverging Destinies: Families in an Era of Increasing Inequality. Ed. by P. Amato, A. Booth, S. McHale, and J. Van Hook. Springer. Chap. 5, pp. 63-82.

Kaufmann, Katja M. (2014). "Understanding the income gradient in college attendance in Mexico: The role of heterogeneity in expected returns". In: Quantitative Economics 5.3, pp. 583-630.

Kiessling, Lukas, Pia Pinger, Jan Bergerhoff, and Philipp Seegers (2019). "Gender Differences in Wage Expectations: Sorting, Children, and Negotiation Styles". Working Paper. 
Kling, Jeffrey R., Jeffrey B. Liebman, and Lawrence F. Katz (2005). "Bullets Don't Got No Name: Consequences of Fear in the Ghetto". In: Discovering Successful Pathways in Children's Development: New Methods in the Study of Childhood and Family Life. Ed. by T.S. Weisner. University of Chicago Press, pp. 243-282.

Laliberté, Jean-William (2018). "Long-term Contextual Effects in Education: Schools and Neighborhoods". Working Paper.

Lamborn, Susie D., Nina S. Mounts, Laurence Steinberg, and Sanford M. Dornbusch (1991). "Patterns of Competence and Adjustment among Adolescents from Authoritative, Authoritarian, Indulgent, and Neglectful Families". In: Child Development 62.5, pp. 1049-1065.

Maccoby, Eleanor E. and John A. Martin (1983). "Socialization in the context of the family: Parent-child interaction". In: Handbook of Child Psychology. Ed. by P. Mussen. Vol. 4. Wiley.

Manski, Charles F. (2004). "Measuring Expectations". In: Econometrica 72.5, pp. 13291376.

Nguyen, Trang (2008). "Information, Role Models and Perceived Returns to Education: Experimental Evidence from Madagascar". Working Paper.

Patacchini, Eleonora and Yves Zenou (2011). "Neighborhood Effects and Parental Involvement in the Intergenerational Transmission of Education". In: Journal of Regional Science 51.5, pp. 987-1013.

Perris, Carlo, Lars Jacobsson, Hakån Lindström, Lars von Knorring, and Hjördis Perris (1980). "Development of a new inventory for assessing memories of parental rearing behaviour". In: Acta Psychiatrica Scandinavica 61.4, pp. 265-274.

Pop-Eleches, Cristian and Miguel Urquiola (2013). "Going to a Better School: Effects and Behavioral Responses". In: American Economic Review 103.4, pp. 1289-1324.

Putnam, Robert D. (2016). Our kids: The American dream in crisis. Simon and Schuster.

Schwarz, Beate, Sabine Walper, Mechthild Gödde, and Stephanie Jurasic (1997). "Dokumentation der Erhebungsinstrumente der 1. Haupterhebung (überarb. Version)". Reports of the research group "Familienentwicklung nach der Trennung" (Vol. 14).

Steinberg, Laurence, Nina S. Mounts, Lamborn Susie D., and Sanford M. Dornbusch (1991). "Authoritative Parenting and Adolescent Adjustment across Vaaried Ecological Niches". In: Journal of Research on Adolescence 1.1, pp. 19-36.

Stinebrickner, Ralph and Todd R. Stinebrickner (2014). "A Major in Science? Initial Beliefs and Final Outcomes for College Major and Dropout". In: Review of Economic Studies 81.1, pp. 426-472.

Wiswall, Matthew and Basit Zafar (2015). "Determinants of College Major Choice: Identification using an Information Experiment". In: Review of Economic Studies 82.2, pp. 791-824. 
Wiswall, Matthew and Basit Zafar (2018a). "Human Capital Investments and Expectations about Career and Family". Working Paper.

- (2018b). "Preference for the Workplace, Investment in Human Capital, and Gender". In: Quarterly Journal of Economics 133.1, pp. 457-507.

Zafar, Basit (2013). "College Major Choice and the Gender Gap". In: Journal of Human Resources 48.3, pp. 545-595.

Zumbuehl, Maria, Thomas Dohmen, and Gerard Pfann (2018). "Parental Involvement and the Intergenerational Transmission of Economic Preferences and Attitudes". Working Paper. 


\section{Appendix - For Online Publication}

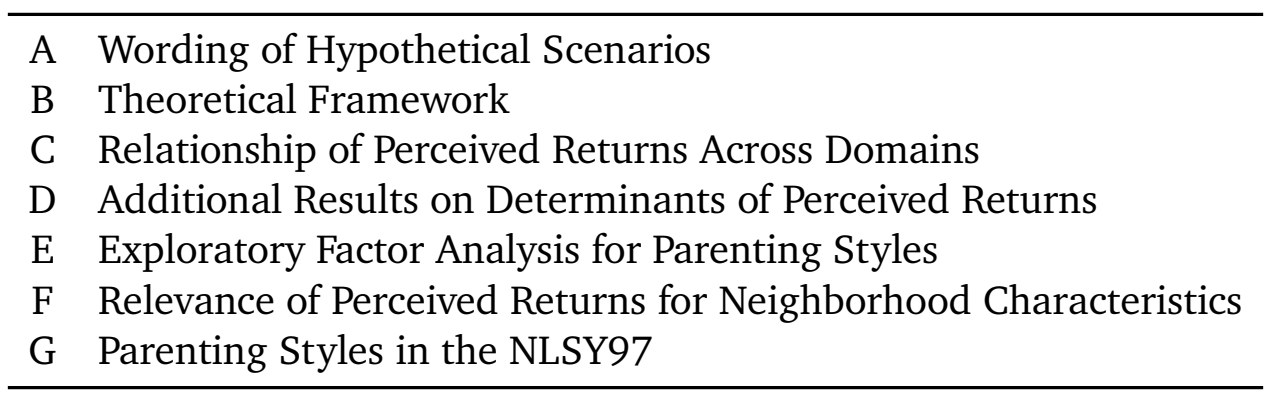




\section{A Wording of Hypothetical Scenarios}

In the following, I present the wording of the main survey instrument containing the hypothetical scenarios. Both the age (6-16 years) as well as the gender of the child in question (male/female) are randomized, resulting in male names (John and Simon) or female names (Sarah and Emily) for the children in the scenarios.

We are interested in your opinion about how important different parenting styles are for the future of children.

For this purpose, we would like to ask you to imagine two average American families, the Joneses and the Smiths, who make decisions how to raise their children. More specifically, we will show you different scenarios, and ask what you think the likely yearly earnings and life satisfaction of their children at age 30 will be. There are no clear right or wrong answers, and we know these questions are difficult. Please try to consider each scenario carefully and tell us what you believe the likely outcome will be.

Mr and Mrs Jones have one son (daughter), John (Sarah). John (Sarah) is 6 (7-16) years old. The Joneses live in a good neighborhood with little crime (10 violent crimes per 10,000 inhabitants) and low unemployment (2\%). Now let's think about the future of John (Sarah). Assuming John (Sarah) is working full-time, what do you expect his (her) gross yearly earnings (in today's USD) to be when he (she) is 30 years old in each of the following scenarios? What do you expect his (her) life satisfaction to be at age 30 on a scale from 1 (low) to 100 (high)?

Scenario 1: John (Sarah)'s parents show him (her) once per week that they like him (her). At the same time, they tell him (her) every other day that he (she) has to obey their decisions.

Scenario 2: John (Sarah)'s parents show him (her) once per week that they like him (her). At the same time, they tell him (her) once per week that he (she) has to obey their decisions.

Scenario 3: John (Sarah)'s parents show him (her) every other day that they like him (her). At the same time, they tell him (her) every other day that he (she) has to obey their decisions.

Scenario 4: John (Sarah)'s parents show him (her) every other day that they like him (her). At the same time, they tell him (her) once per week that he (she) has to obey their decisions. 
Now imagine a different family, the Smiths. In many respects, the Smiths are very similar to the Joneses. For example, Mr and Mrs Smith have one son (daughter), Simon (Emily), who is also 6 (7-16) years old and as smart as John (Sarah). Mr and Mrs Smith also have similar levels of income and education as Mr and Mrs Jones and spend as much time and money on raising their child. However, there is one difference. Unlike the Joneses, the Smiths live in a bad neighborhood with much crime (60 violent crimes per 10,000 inhabitants per year) and high unemployment (10\%). Assuming Simon (Emily) is working full-time, what do you expect his (her) gross yearly earnings (in today's USD) to be when he (she) is 30 years old in each of the following scenarios? What do you expect his (her) life satisfaction to be at age 30 on a scale from 1 (low) to 100 (high)?

Scenario 5: Simon (Emily)'s parents show him (her) once per week that they like him (her). At the same time, they tell him (her) every other day that he (she) has to obey their decisions.

Scenario 6: Simon (Emily)'s parents show him (her) once per week that they like him (her). At the same time, they tell him (her) once per week that he (she) has to obey their decisions.

Scenario 7: Simon (Emily)'s parents show him (her) every other day that they like him (her). At the same time, they tell him (her) every other day that he (she) has to obey their decisions.

Scenario 8: Simon (Emily)'s parents show him (her) every other day that they like him (her). At the same time, they tell him (her) once per week that he (she) has to obey their decisions. 


\section{B Theoretical Framework}

There is accumulating evidence that both the way in which parents raise their children (e.g., Cobb-Clark, Salamanca, and Zhu, 2019; Falk et al., forthcoming) as well as neighborhoods in which children are growing up (Chetty and Hendren, 2018a, b, e.g.,) have long-lasting effects on the development of children and their life outcomes. In this paper, I study parents' perceptions about the returns to these factors, which may or may not coincide with their actual returns. Yet, they are important as parents base their actual decisions on their beliefs and perceived returns.

As a point of departure, I consider a simple stylized model, in which parental investments as well as the environments/neighborhood impact the skill formation of children and thus their long-term outcomes such as earnings and well-being. Let $\theta_{t+1}$ denote children's skills in period $t+1$ (adulthood), $I_{t}$ denote parents' time investments, and $E_{t}$ captures the quality of the environment in which a family is living in (e.g., neighborhood quality) during childhood. Investments and the environment form children's skills according to the following function:

$$
\theta_{t+1}=f\left(I_{t}, E_{t} ; \psi\right)
$$

in which $\psi$ denotes a vector of parameters which describe the productivity of investments and the environment in the skill formation process, which I conceptualize as the parenting styles that parents adopt in raising their children.1. I assume that the skill formation process $f(\cdot)$ is continuous, monotonically increasing, and concave in its arguments.

Furthermore, I assume that there exist a monotonically increasing function $g(\cdot)$ mapping skills in adulthood, $\theta_{t+1}$, into economic outcomes, $y_{t+1}$, such as earnings or life satisfaction. Taken together, this yields a function $h=g \circ f$ describing how inputs - time investments, environments and parenting styles - translate into economic outcomes - earnings and life satisfaction. Parents base their decisions which parenting style to adopt and in which neighborhood to live not on the actual consequences, which are rather difficult to anticipate, but rather on their perceptions of the tech-

${ }^{1}$ Thus, this assumption differs from, e.g., Falk et al. (forthcoming) who model parenting styles as an additional investment of parents besides time investments, and is more closely aligned to the idea of the quality of parenting for a given amount of time investments. Nonetheless, depending on the functional form, the model presented here nests skill formation functions that conceptualize parenting styles as an additional input in the skill production function rather than a parameter. See also Cunha (2015) for a similar conceptualization of parenting styles as parameters of the skill production function. Moreover, the skill formation function in equation (4) can easily extended to allow for more than one period in childhood to accommodate sensitive periods during childhood in which investments are more productive than in others (Cunha and Heckman, 2007) by indexing $\psi$ with $t$. 
nology of skill formation. In particular, parents choose their investments, parenting styles, and neighborhoods based on expected outcomes $y_{t+1}=h_{i}\left(I_{t}, E_{t}, \psi\right)$

The scenarios described in Section 2 therefore vary the quality of the neighborhood in which a hypothetical family lives, as well as the parenting style, and hold their time investments constant. Thus, by comparing parental beliefs across scenarios, I can recover their perceptions about the marginal product of improving the neighborhood environment of children

$$
\frac{\partial h_{i}(\cdot)}{\partial E_{t}}
$$

holding parental investments and the parenting style constant, and the marginal product of different dimensions of parenting styles

$$
\frac{\partial h_{i}(\cdot)}{\partial \psi^{k}}
$$

for $k \in\{w, c\}$, where $w$ corresponds to the warmth dimension of parenting styles, whereas $c$ corresponds to the control dimension.

Moreover, by comparing cross-derivatives of changes in the neighborhood quality as well as changes in parenting styles, I am able to study whether parents perceive neighborhoods and the two dimensions of parenting styles, warmth and control, as substitutes (i.e., negative cross-derivatives), complements (i.e., positive crossderivatives), or independent of each other (i.e., zero cross-derivatives):

$$
\frac{\partial^{2} h_{i}(\cdot)}{\partial E_{t} \partial \psi^{w}} \lesseqgtr 0, \quad \frac{\partial^{2} h_{i}(\cdot)}{\partial E_{t} \partial \psi^{c}} \lesseqgtr 0, \quad \frac{\partial^{2} h_{i}(\cdot)}{\partial \psi^{w} \partial \psi^{c}} \lesseqgtr 0 .
$$

If, for example, parents perceive that parenting can partly compensate for the lack of a good environment, the first two terms would be negative. Similarly, if parents perceive that parenting styles pairing high levels of warmth with high levels of control as in authoritative parenting styles has additional benefits, the last term would be positive.

For each of the scenarios in the survey, I vary one of the factors (warmth or control dimension of parenting styles, neighborhood quality) and elicit two outcomes that allow me to determine the sign and magnitude of these partial derivatives in two domains: children's earnings and their life satisfaction (on a scale from 1 to 100) at age 30. Eliciting both of these long-term outcomes has several advantages: First, these outcomes allow me to easily elicit parents' beliefs about the consequences of growing up in a good neighborhood and being raised with a particular parenting style 
while holding other parental investments fixed. Second, they allow me to calculate parents' perceived returns to these factors in a straightforward manner. In fact, the scenarios are constructed to allow for comparisons that change only one dimension at a time. Third, I can test whether my results only apply to a specific domain in which these outcomes were elicited, or whether they are similar across different domains. Eliciting parental beliefs based on the hypothetical scenarios thus allows me to shed light on the perceived form of the technology of skill formation. 


\section{Relationship of Perceived Returns Across Domains}

Figure C.1: Rank correlation of earnings and life satisfaction expectations

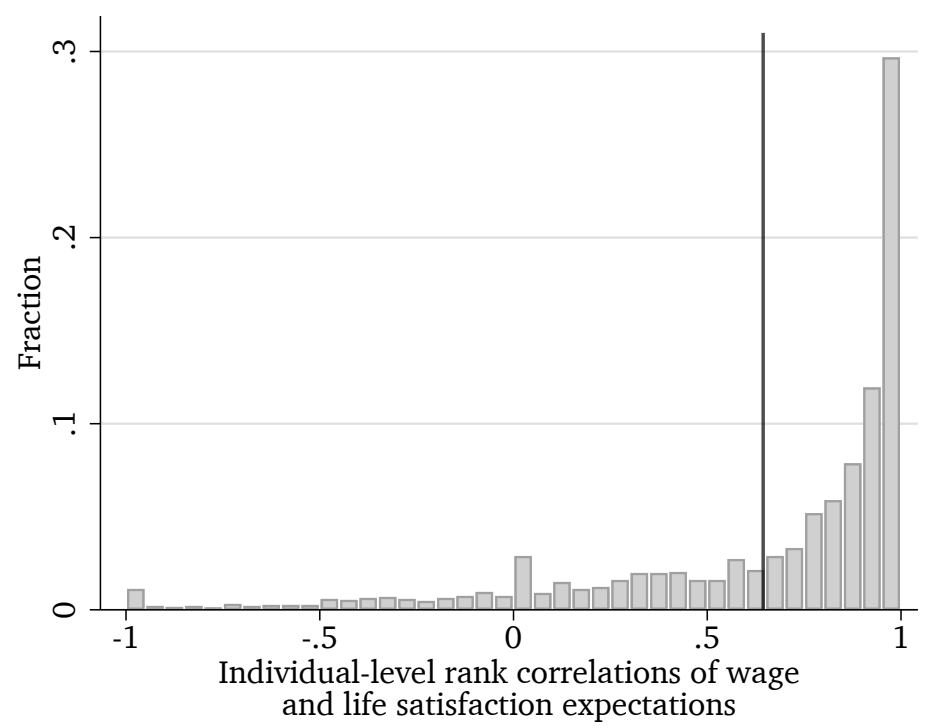

Notes: This figure presents the distribution of individual-level rank correlations of earnings and life satisfaction expectations. The red line indicates the mean rank correlation across respondents.

Table C.1: Relationship of perceived returns in earnings and life satisfaction domain

\begin{tabular}{|c|c|c|c|c|c|c|}
\hline & \multicolumn{2}{|c|}{$R_{\text {warmth }, i}^{L S}$} & \multicolumn{2}{|c|}{$R_{\text {control }, i}^{L S}$} & \multicolumn{2}{|c|}{$R_{\text {neighb., } i}^{L S}$} \\
\hline & (1) & (2) & (3) & (4) & (5) & (6) \\
\hline$R_{\text {warmth }, i}$ & $\begin{array}{c}0.652^{* * *} \\
(0.036)\end{array}$ & $\begin{array}{c}0.651^{* * *} \\
(0.036)\end{array}$ & & & & \\
\hline$R_{\text {control }, i}$ & & & $\begin{array}{c}0.534^{* * *} \\
(0.040)\end{array}$ & $\begin{array}{c}0.533^{* * *} \\
(0.040)\end{array}$ & & \\
\hline$R_{n e i g h b ., i}$ & & & & & $\begin{array}{c}0.376^{* * *} \\
(0.035)\end{array}$ & $\begin{array}{c}0.377^{* * *} \\
(0.035)\end{array}$ \\
\hline Controls & No & Yes & No & Yes & No & Yes \\
\hline Individuals & 2119 & 2119 & 2119 & 2119 & 2119 & 2119 \\
\hline$R^{2}$ & .28 & .28 & .2 & .2 & .11 & .11 \\
\hline
\end{tabular}

Notes: This table presents regressions of individual-level perceived returns in the life satisfaction domain $\left(R_{k, i}^{L S}\right)$ on perceived returns in the monetary domain $\left(R_{k, i}\right)$ for $k=$ warmth, control, neighborhood. Returns are calculated from estimating equation (1) for each individual using either expected earnings $\left(R_{k, i}\right)$ or expected life satisfaction $\left(R_{k, i}^{L S}\right)$ at age 30 as an outcome. Controls include respondent's age and gender, as well as indicators for being white, having a college degree, being employed, and being a single parent, log-household income, number of children in the household, and the share of children being female as in Table 3 . Robust standard errors in parentheses. *, **, and *** denote significance at the 10,5 , and 1 percent level. 
Table C.2: Parental beliefs about perceived returns in the life satisfaction domain

\begin{tabular}{lccccccc}
\hline & \multicolumn{7}{c}{ log. of expected life satisfaction at age $30\left(\log \left(l s_{i j}\right)\right)$} \\
\cline { 2 - 8 } & $(1)$ & $(2)$ & $(3)$ & $(4)$ & $(5)$ & $(6)$ & $(7)$ \\
\hline High warmth & $0.201^{* * *}$ & $0.201^{* * *}$ & $0.201^{* * *}$ & $0.180^{* * *}$ & $0.180^{* * *}$ & $0.180^{* * *}$ & $0.183^{* * *}$ \\
& $(0.009)$ & $(0.009)$ & $(0.009)$ & $(0.011)$ & $(0.011)$ & $(0.011)$ & $(0.011)$ \\
High control & -0.004 & -0.004 & -0.004 & $-0.033^{* * *}$ & $-0.033^{* * *}$ & $-0.033^{* * *}$ & $-0.030^{* * *}$ \\
& $(0.005)$ & $(0.005)$ & $(0.005)$ & $(0.008)$ & $(0.008)$ & $(0.008)$ & $(0.009)$ \\
Good neighborhood & $0.145^{* * *}$ & $0.145^{* * *}$ & $0.145^{* * *}$ & $0.159^{* * *}$ & $0.159^{* * *}$ & $0.159^{* * *}$ & $0.162^{* * *}$ \\
& $(0.010)$ & $(0.010)$ & $(0.010)$ & $(0.012)$ & $(0.012)$ & $(0.012)$ & $(0.012)$ \\
High warmth & & & & $0.063^{* * *}$ & $0.063^{* * *}$ & $0.063^{* * *}$ & $0.057^{* * *}$ \\
$\quad \times$ High control & & & & $(0.012)$ & $(0.012)$ & $(0.012)$ & $(0.014)$ \\
High warmth & & & & $-0.022^{* *}$ & $-0.022^{* *}$ & $-0.022^{* *}$ & $-0.028^{* * *}$ \\
$\quad \times$ Good neighborhood & & & & $(0.009)$ & $(0.009)$ & $(0.009)$ & $(0.011)$ \\
High control & & & & -0.006 & -0.006 & -0.006 & -0.011 \\
$\quad \times$ Good neighborhood & & & & $(0.008)$ & $(0.008)$ & $(0.008)$ & $(0.011)$ \\
High warmth $\times$ High control & & & & & & & 0.011 \\
$\quad \times$ Good neighborhood & & & & & & & $(0.015)$ \\
\hline Mean exp. life satis. (0-100) & 53 & 53 & 53 & 53 & 53 & 53 & 53 \\
Controls for heterogeneity & No & Controls & $\mathrm{FE}$ & No & Controls & $\mathrm{FE}$ & $\mathrm{FE}$ \\
Observations & 16952 & 16952 & 16952 & 16952 & 16952 & 16952 & 16952 \\
Individuals & 2119 & 2119 & 2119 & 2119 & 2119 & 2119 & 2119 \\
$R^{2} \quad$ & .021 & .034 & .8 & .021 & .034 & .8 & .8 \\
\hline
\end{tabular}

Notes: This table presents least squares regressions of log life satisfaction expectations based on equation (1). Columns (1) through (3) focus on first-order effects, while columns (4) to (6) add interactions. Standard errors clustered by respondent in parentheses. *, **, and *** denote significance at the 10,5 , and 1 percent level. 


\section{Additional Results on Determinants of Perceived Re- turns}

To what extent are the associations reported in Section 5 driven by zero responses as shown in Figure 33. Table D.1 shows that respondents who perceive no returns in one dimension are also more likely to also report zero returns in another. This pattern is especially pronounced for both parenting dimensions, suggesting that these individuals do not expect parenting to matter for long-term outcomes of children. Panel A of Table D.2 shows that fathers, older respondents, as well as those with fewer children and who do not believe that skills are malleable are more likely to report zero responses in the parenting domains. Panel B shows how the results in Table 8 would change once I restrict the sample to respondents perceiving non-zero returns. The patterns are qualitatively and quantitatively similar to the whole sample.

Table D.1: Correlations of zero perceived returns

\begin{tabular}{lccc}
\hline & Warmth & Control & Neighb. \\
\hline Warmth & 1.000 & & \\
Control & $0.823^{* * *}$ & 1.000 & \\
Neighb. & $0.365^{* * *}$ & $0.385^{* * *}$ & 1.000 \\
\hline
\end{tabular}

Notes: This table presents correlations of indicators for whether a respondent expects zero returns to warmth, control, or neighborhoods. *, **, and *** denote significance at the 10,5 , and 1 percent level.

The perceived returns analyzed here are subject to measurement error as they are inferred from eight observations only. While the main analysis in Section 5 uses the perceived returns in outcomes, for which measurement error just reduces the efficiency of the estimates, I can also use the perceived returns as explanatory variables and adopt the measurement error correction as discussed in Section 3, Rather than using measures of parenting styles as outcomes, I aim at predicting individual characteristics using the perceived returns from the earnings and life satisfaction domain. As before, I duplicate all observations and check whether perceived returns can predict a specific characteristic conditional on all other characteristics by estimating 
Table D.2: Perceived returns accounting for zero responses

\begin{tabular}{|c|c|c|c|c|c|c|}
\hline & \multicolumn{3}{|c|}{ (A) Zero returns } & \multicolumn{3}{|c|}{ (B) Returns excluding zeros } \\
\hline & $(1)$ & (2) & (3) & (4) & (5) & (6) \\
\hline & Parenting & Neighb. & All & $R_{\text {warmth }, i}$ & $R_{\text {control }, i}$ & $R_{\text {neighb., } i}$ \\
\hline \multicolumn{7}{|l|}{ Sociodemographic characteristics } \\
\hline \multirow[t]{2}{*}{ Female } & $-0.037^{*}$ & -0.001 & -0.015 & $0.067^{* * *}$ & 0.020 & $0.060^{* * *}$ \\
\hline & $(0.021)$ & $(0.016)$ & $(0.013)$ & $(0.021)$ & $(0.018)$ & $(0.022)$ \\
\hline \multirow[t]{2}{*}{ Age } & $0.004^{* * *}$ & 0.001 & 0.001 & 0.000 & -0.001 & $0.003^{* *}$ \\
\hline & $(0.001)$ & $(0.001)$ & $(0.001)$ & $(0.001)$ & $(0.001)$ & $(0.001)$ \\
\hline \multirow{2}{*}{ White } & 0.010 & $0.038^{* *}$ & $0.024^{*}$ & $0.061^{* * *}$ & 0.022 & 0.020 \\
\hline & $(0.022)$ & $(0.017)$ & $(0.013)$ & $(0.024)$ & $(0.019)$ & $(0.025)$ \\
\hline \multirow[t]{2}{*}{ College degree } & -0.028 & -0.001 & -0.011 & -0.010 & -0.003 & -0.000 \\
\hline & $(0.021)$ & $(0.018)$ & $(0.014)$ & $(0.023)$ & $(0.019)$ & $(0.022)$ \\
\hline \multirow[t]{2}{*}{ Employed } & -0.035 & -0.015 & -0.016 & -0.039 & -0.005 & -0.029 \\
\hline & $(0.023)$ & $(0.018)$ & $(0.015)$ & $(0.025)$ & $(0.020)$ & $(0.025)$ \\
\hline \multirow[t]{2}{*}{ log(Household income) } & 0.003 & 0.005 & 0.002 & 0.025 & 0.006 & -0.008 \\
\hline & $(0.015)$ & $(0.012)$ & $(0.010)$ & $(0.017)$ & $(0.015)$ & $(0.018)$ \\
\hline \multirow[t]{2}{*}{ Single parent } & 0.009 & 0.005 & 0.007 & $0.064^{* *}$ & -0.003 & 0.016 \\
\hline & $(0.027)$ & $(0.022)$ & $(0.018)$ & $(0.031)$ & $(0.025)$ & $(0.030)$ \\
\hline \multirow[t]{2}{*}{ Number of children } & $-0.029^{* * *}$ & -0.005 & $-0.015^{* * *}$ & 0.005 & -0.005 & 0.001 \\
\hline & $(0.009)$ & $(0.008)$ & $(0.005)$ & $(0.009)$ & $(0.008)$ & $(0.010)$ \\
\hline \multirow[t]{2}{*}{ Share of female children } & 0.009 & 0.022 & 0.022 & -0.008 & 0.003 & 0.017 \\
\hline & $(0.026)$ & $(0.021)$ & $(0.017)$ & $(0.027)$ & $(0.023)$ & $(0.025)$ \\
\hline \multicolumn{7}{|l|}{ Parenting values } \\
\hline \multirow[t]{2}{*}{ Altruism towards child (std.) } & -0.007 & -0.001 & -0.007 & $0.023^{* *}$ & -0.007 & $0.033^{* * *}$ \\
\hline & $(0.010)$ & $(0.008)$ & $(0.007)$ & $(0.009)$ & $(0.008)$ & $(0.010)$ \\
\hline \multirow[t]{2}{*}{ Paternalism towards child (std.) } & $-0.024^{* *}$ & -0.007 & $-0.013^{*}$ & -0.004 & $0.018^{* *}$ & -0.000 \\
\hline & $(0.010)$ & $(0.008)$ & $(0.007)$ & $(0.011)$ & $(0.009)$ & $(0.011)$ \\
\hline \multirow[t]{2}{*}{ Malleability of skills (std.) } & $-0.020^{* *}$ & $-0.015^{*}$ & $-0.012^{*}$ & $0.034^{* * *}$ & $0.015^{*}$ & $0.054^{* * *}$ \\
\hline & $(0.010)$ & $(0.008)$ & $(0.006)$ & $(0.010)$ & $(0.009)$ & $(0.010)$ \\
\hline Mean of dependent variable & .23 & .14 & .08 & .21 & 0 & .24 \\
\hline Individuals & 2109 & 2109 & 2109 & 1626 & 1626 & 1821 \\
\hline$R^{2}$ & .019 & .0063 & .012 & .028 & .0074 & .033 \\
\hline
\end{tabular}

Notes: This table presents regressions of an indicator of zero perceived returns (Panel A) or individuallevel perceived returns excluding those with zero returns (Panel B) on sociodemographic characteristics and parenting values according to equation 2. Individual-level perceived returns are estimated based on equation (1) for each individual separately. The dependent variable in column (1) corresponds to an indicator equal to one if returns to both warmth and control are perceived to be zero, while column (2) focuses on zero perceived returns in the neighborhood dimension. Column (3) checks for all three dimensions simultaneously. Columns (4) to (6) correspond to columns (4) to (6) of Table 8, but exclude individuals that report zero perceived returns according to column (1) and (2), respectively. Robust standard errors in parentheses. $*, * *$, and $* * *$ denote significance at the 10,5 , and 1 percent level.

$$
\begin{aligned}
& \left(\begin{array}{c}
x_{i} \\
x_{i}
\end{array}\right)=\left(\begin{array}{c}
\delta_{0}^{E} \\
\delta_{0}^{L S}
\end{array}\right)+\delta_{1}\left(\begin{array}{c}
R_{k, i}^{E} \\
R_{k, i}^{L S}
\end{array}\right)+\left(\begin{array}{c}
\delta_{2}^{E} \tilde{X}_{i} \\
\delta_{2}^{L S} \tilde{X}_{i}
\end{array}\right)+v_{k, i} \\
& \text { instrumenting }\left(\begin{array}{c}
R_{k, i}^{E} \\
R_{k, i}^{L S}
\end{array}\right) \text { with } Z=\left(\begin{array}{cc}
R_{k, i}^{L S} & 0_{N} \\
0_{N} & R_{k, i}^{E}
\end{array}\right) .
\end{aligned}
$$


Here, $k$ indicates the dimension under consideration $(k=$ warmth, control, neighborhood), $\tilde{X}_{i}$ denotes all sociodemographic characteristics excluding the one that is used as an outcome, and standard errors will be bootstrapped. Table D.3 presents the results of this exercise. Each cell corresponds to a coefficient from a regression of equation (8): An increase of one standard deviation in perceived returns in the warmth or neighborhood dimension is associated with a 3.6-4.0 percentage point increase in the probability of being female and parenting values show similar patterns as before.

Table D.3: Determinants of individual-level perceived returns using instrumented perceived returns

\begin{tabular}{lccc}
\hline & \multicolumn{3}{c}{ Coefficients on perc. returns } \\
\cline { 2 - 4 } & $(1)$ & $(2)$ & $(3)$ \\
& $R_{\text {warmth }, i}$ & $R_{\text {control, } i}$ & $R_{\text {neighb., } i}$ \\
\hline Sociodemographic characteristics & & & \\
Female & $0.036^{* * *}$ & 0.022 & $0.040^{*}$ \\
& $(0.013)$ & $(0.016)$ & $(0.022)$ \\
Age & -0.186 & -0.193 & $0.775^{* *}$ \\
& $(0.217)$ & $(0.273)$ & $(0.336)$ \\
White & $0.040^{* * *}$ & 0.013 & 0.004 \\
& $(0.013)$ & $(0.015)$ & $(0.021)$ \\
College degree & -0.014 & -0.018 & -0.011 \\
& $(0.013)$ & $(0.015)$ & $(0.021)$ \\
Employed & -0.026 & -0.012 & -0.025 \\
& $(0.012)$ & $(0.014)$ & $(0.020)$ \\
log(Household income) & 0.015 & 0.028 & 0.026 \\
Single parent & $0.020)$ & $(0.024)$ & $(0.032)$ \\
& 0.011 & -0.002 & 0.015 \\
Number of children & $(0.011)$ & $(0.013)$ & $(0.017)$ \\
Share of female children & $0.068^{* *}$ & -0.028 & 0.040 \\
& $(0.033)$ & $(0.039)$ & $(0.056)$ \\
Parenting values & -0.012 & 0.001 & -0.017 \\
Altruism towards child (std.) & $(0.011)$ & $(0.014)$ & $(0.017)$ \\
Paternalism towards child (std.) & $0.088^{* * *}$ & -0.027 & $0.120^{* *}$ \\
& $(0.027)$ & $(0.034)$ & $(0.048)$ \\
Malleability of skills (std.) & 0.035 & $0.128^{* * *}$ & 0.022 \\
& $0.137^{* * * *}$ & $(0.036)$ & $(0.048)$ \\
& $(0.030)$ & $(0.034)$ & $0.249^{* * *}$ \\
& $0.047)$ \\
\hline
\end{tabular}

Notes: This table presents regressions of a respondent's characteristic $x_{i}$ on the instrumented and standardized perceived return and all other individual characteristics based on equation (8). Each cell reports the coefficient of the perceived returns from a separate regression with the characteristics on the left as the dependent variable. Column (1) uses perceived returns to warmth, column (2) perceived returns to control, and column (3) perceived returns to neighborhoods as the regressor of interest. All specifications include the non-used variables as additional controls. Bootstrapped standard errors form 1,000 repetitions in parentheses. $* * *$, and $* * *$ denote significance at the 10,5 , and 1 percent level. 


\section{E Exploratory Factor Analysis for Parenting Styles}

In the survey, I use two established scales by Perris et al. (1980) and Schwarz et al. (1997) to measure the warmth and control dimension of parenting styles. These scales are frequently used in the literature (e.g., Falk et al., forthcoming) and part of large-scale panel studies such as the German Socioeconomic Panel (SOEP). Here, I briefly show that the 3-item warmth scale and the 4-item control scale indeed capture two separate dimensions of parenting styles. To do this, I use all seven items in an explanatory factor analysis. As shown in Figure E.1, I indeed find two factors with an eigenvalue larger than one. Table E.1 presents the corresponding factor loadings after a Varimax rotation. Reassuringly, the first factor almost exclusively loads on items from the warmth scale, while the second factor loads on items of the control scale.

Figure E.1: Scree plot of parenting style items

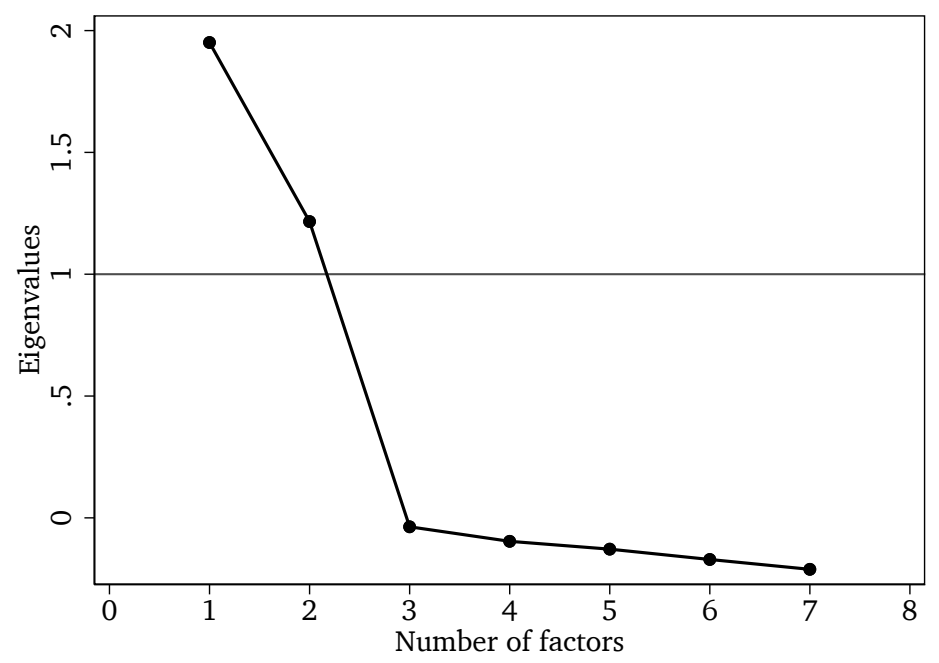

Notes: This figure presents a scree plot of the eigenvalues from an exploratory factor analysis using seven items based on Perris et al. (1980) and Schwarz et al. (1997) to measure parenting styles in the warmth and control dimensions, respectively.

In the main analysis of the paper, I therefore use the first principal component for each of the two scales. Hence, I allow for a potential correlation of the two dimensions of parenting styles (the correlation of the two factors equals 0.164). 
Table E.1: Rotated factor loadings of actual parenting styles

\begin{tabular}{lcc}
\hline & \multicolumn{2}{c}{$\begin{array}{c}\text { Rotated } \\
\text { factor loadings }\end{array}$} \\
\cline { 2 - 3 } & $\begin{array}{c}(1) \\
\text { Warmth }\end{array}$ & $\begin{array}{c}(2) \\
\text { Control }\end{array}$ \\
& & \\
\hline $\begin{array}{l}\text { Warmth measures (Perris et al., 1980) } \\
\text { (1) I show my son/daughter with words and gestures }\end{array}$ & 0.72 & 0.06 \\
that I like him/her & & 0.74 \\
(2) I cheer up my son/daughter when he/she is sad & 0.09 \\
(3) I praise my son/daughter & 0.75 & 0.07 \\
$\begin{array}{l}\text { Control measures (Schwarz et al., 1997) } \\
\text { (4) I tend to be a strict parent }\end{array}$ & 0.08 & 0.57 \\
(5) If my son/daughter does something against my & 0.06 & 0.68 \\
will, I punish him/her & & \\
(6) I make it clear to my son/daughter that he/she is & 0.12 & 0.67 \\
not to break the rules or question my decisions & & \\
(7) I never waive from my rules & 0.07 & 0.51 \\
\hline
\end{tabular}

Notes: This table presents rotated factor loadings from an exploratory factor analysis using seven items based on Perris et al. (1980) and Schwarz et al. (1997) to measure parenting styles in the warmth and control dimensions, respectively. 


\section{F Relevance of Perceived Returns for Neighborhood Characteristics}

In this section, I examine whether estimated returns in the neighborhood dimension are related to the quality of the neighborhood a family is living in. I use two approaches to answer this question. First, the survey elicits the parents' agreement to three statements: (i) "My neighborhood is a good place to raise children", (ii) "I feel safe in my neighborhood", and (iii) "My child attends a school of good quality" on a 5-point scale. I extract a factor from these statements as a measure of the subjective neighborhood quality. Second, based on respondents' zipcodes, I merge county-level neighborhood characteristics from Chetty and Hendren (2018a b) to my survey data, and perform a second factor analysis that reveals two factors with eigenvalues larger than 1: a first factor capturing economic conditions in a neighborhood (NB 1), and a second factor (NB 2) related to measures of segregation and urbanization. Figure F.1 presents the corresponding scree plot, while Table F.1 shows the rotated factor loadings of the underlying items. Table F.2 presents analogous estimates to Table 10 using both the subjective assessment or objective measures of neighborhood quality as outcome variables.1

Figure F.1: Scree plot of parenting style items

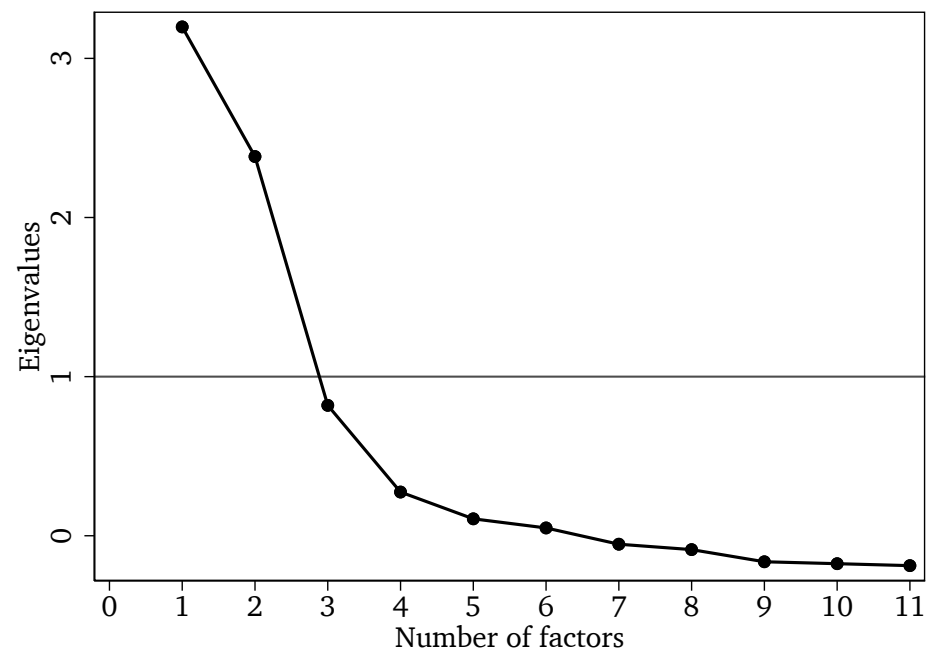

Notes: This figure presents a scree plot of the eigenvalues from an exploratory factor analysis using 11 neighborhood characteristics taken from Chetty and Hendren (2018ab).

\footnotetext{
${ }^{1}$ One caveat of this approach to keep in mind is that some neighborhood characteristics are historical data and thus may have changed over time. Yet, Chetty et al. (2018) document that these characteristics are relatively stable over time and good predictors of today's conditions.
} 
Table F.1: Rotated factor loadings of actual parenting styles

\begin{tabular}{|c|c|c|}
\hline & \multicolumn{2}{|c|}{$\begin{array}{l}\text { Rotated } \\
\text { factor loadings }\end{array}$} \\
\hline & $(1)$ & $(2)$ \\
\hline & NB1 & NB2 \\
\hline $\begin{array}{l}\text { (1) Fraction of residents having a college degree or } \\
\text { more (2010) }\end{array}$ & 0.73 & -0.01 \\
\hline (2) Median household income (2016) & 0.89 & 0.00 \\
\hline (3) Poverty rate (2010) & -0.73 & 0.24 \\
\hline $\begin{array}{l}\text { (4) Share of single-headed households with children } \\
\text { (2010) }\end{array}$ & -0.68 & 0.20 \\
\hline $\begin{array}{l}\text { (5) Avg. school-district level standardized test scores } \\
\text { in 3rd grade (2013) }\end{array}$ & 0.44 & -0.25 \\
\hline (6) Census form return rate (2010) & 0.38 & -0.53 \\
\hline $\begin{array}{l}\text { (7) Share of working adults with commuting times of } \\
15 \text { minutes or less (2010) }\end{array}$ & 0.13 & 0.14 \\
\hline$(8)$ & -0.29 & -0.32 \\
\hline (9) Population density (per square mile; 2010) & -0.02 & 0.20 \\
\hline (10) Share of population born outside the U.S. (2010) & 0.12 & 0.74 \\
\hline (11) Share of people who are not white (2010) & -0.22 & 0.85 \\
\hline
\end{tabular}

Notes: This table presents rotated factor loadings from an exploratory factor analysis using 11 neighborhood characteristics taken from Chetty and Hendren (2018a b).

I find that only perceived returns in the monetary domain are significantly associated with the subjectively assessed quality of a neighborhood. Returns in the life satisfaction domain or the IV strategy do not reveal a significant association. Yet, when looking at objective measures of the neighborhood quality in columns (4) and (5), I find that higher perceived returns to neighborhoods are associated positively, but not significantly with economic conditions of a neighborhood ( $p=0.169$ ). They are, however, negatively related with its segregation. Although parental beliefs do not predict subjective neighborhood assessments, they are related to objective measures of the neighborhood characteristics. This suggests that respondents are not necessarily aware how their environment shapes their own assessments of the return to neighborhoods. Taken together, parental beliefs are not only systematically related to actual parenting styles, but also associated with characteristics of the parents' place of residence. This supports the conjecture that these parental beliefs are a fundamental part of parental decision-making processes. 
Table F.2: Relevance of perceived returns for neighborhood quality

\begin{tabular}{|c|c|c|c|c|c|}
\hline & \multicolumn{3}{|c|}{ Subjective Neighborhood Quality } & \multirow{2}{*}{$\frac{\text { NB } 1}{(4)}$} & \multirow{2}{*}{$\frac{\text { NB } 2}{(5)}$} \\
\hline & (1) & (2) & (3) & & \\
\hline & $\begin{array}{l}\text { Expected } \\
\text { earnings }\end{array}$ & $\begin{array}{l}\text { Expected } \\
\text { Life Satis. }\end{array}$ & IV & IV & IV \\
\hline$R_{\text {neighb., } i}$ (std.) & $\begin{array}{l}0.043^{* *} \\
(0.020)\end{array}$ & $\begin{array}{l}-0.005 \\
(0.020)\end{array}$ & $\begin{array}{c}0.058 \\
(0.042)\end{array}$ & $\begin{array}{c}0.062 \\
(0.043)\end{array}$ & $\begin{array}{c}-0.161^{* * *} \\
(0.044)\end{array}$ \\
\hline Controls & Yes & Yes & Yes & Yes & Yes \\
\hline Observations & 2104 & 2104 & 4208 & 4164 & 4164 \\
\hline Individuals & 2104 & 2104 & 2104 & 2082 & 2082 \\
\hline$R^{2}$ & .11 & .11 & .104 & .135 & .113 \\
\hline
\end{tabular}

Notes: This table examines associations of perceived returns and measures of the actual neighborhood quality. Columns (1) to (3) present the results for the respondents' subjective assessments of the quality of their neighborhood. The outcome variable is a factor constructed from agreement to the three statements (i) "My neighborhood is a good place to raise children", (ii) "I feel safe in my neighborhood", and (iii) "My child attends a school of good quality". Columns (1) and (2) use returns in the expected earnings and expected life satisfaction domains, while column (3) implements the IV strategy based on equation (3) to correct for measurement error in perceived returns using the two return measures as instruments for each other. Columns (4) and (5) present corresponding results for objective measures of a neighborhood's characteristics based on respondents' postcodes using ORIVs. NB 1 refers to a factor capturing economic conditions in an area, while NB 2 is related to measures of segregation and urbanization. All specifications include controls for respondent's age and gender, as well as indicators for being white, having a college degree, being employed, and being a single parent, log-household income, number of children in the household, and the share of children being female as in Table 3 . Bootstrapped standard errors from 1,000 repetitions in parentheses. *, **, and *** denote significance at the $10 \%, 5 \%$, and $1 \%$ level. 


\section{G Parenting Styles in the National Longitudinal Sur- vey of Youth 1997 (NLSY97)}

Table G.1: Gender differences in parenting styles (NLSY97)

\begin{tabular}{lccccc}
\hline & \multicolumn{2}{c}{ Mother's Par. Style } & & \multicolumn{2}{c}{ Father's Par. Style } \\
\cline { 2 - 3 } \cline { 6 - 6 } & $(1)$ & $(2)$ & & $(3)$ & $(4)$ \\
& $\log ($ earnings $)$ & HS GPA & & $\log ($ earnings $)$ & HS GPA \\
\hline Warmth & $0.104^{* *}$ & $0.271^{* * *}$ & & $0.147^{* * *}$ & $0.294^{* * *}$ \\
Control & $(0.045)$ & $(0.043)$ & & $(0.042)$ & $(0.040)$ \\
& 0.020 & $0.121^{* *}$ & & $0.076^{*}$ & $0.088^{* *}$ \\
Warmth $\times$ Control & $(0.051)$ & $(0.048)$ & & $(0.046)$ & $(0.043)$ \\
& 0.026 & -0.018 & & -0.021 & 0.002 \\
& $(0.060)$ & $(0.057)$ & & $(0.057)$ & $0.055)$ \\
\hline Observations & 5046 & 5832 & & 4873 & 5645 \\
$R^{2}$ & .0037 & .017 & & .0061 & .023 \\
\hline
\end{tabular}

Notes: This table uses data from the National Longitudinal Survey of Youth 1997 and regresses the child's log earnings in 2013 (i.e., when they are on average 30 years old) on the child's reports of each of its parents' parenting style. Columns (1) and (2) focus on the mother's warmth and control, while columns (3) and (4) report analogous regressions for fathers. Robust standard errors in parentheses. $*, * *$, and *** denote significance at the 10, 5, and 1 percent level.

Table G.2: Gender differences in parenting styles (NLSY97)

\begin{tabular}{lccccc}
\hline & \multicolumn{2}{c}{ Warmth } & & \multicolumn{2}{c}{ Control } \\
\cline { 2 - 3 } \cline { 5 - 6 } & $(1)$ & $(2)$ & & $(3)$ & $(4)$ \\
\hline Mother & $0.057^{* * *}$ & $0.058^{* * *}$ & & $0.018^{* * *}$ & $0.017^{* * *}$ \\
& $(0.004)$ & $(0.004)$ & & $(0.003)$ & $(0.004)$ \\
\hline Mean of dependent variable & .65 & .65 & & .55 & .55 \\
Observations & 16968 & 12310 & & 16968 & 12310 \\
$R^{2}$ & .0036 & .035 & & .00032 & .027 \\
\hline
\end{tabular}

Notes: This table uses data from the National Longitudinal Survey of Youth 1997 and regresses the child's report of each of its parents' parenting style (measured by binary indicators) on an indicator for mothers. Columns (1) and (2) focus on the warmth dimension, while columns (3) and (4) focus on control. Control variables include the age and gender of the child, the parent's education, the log household income, and an indicator for whether both parents are present at home. Standard errors clustered on child-level in parentheses. * $* *$, and $* * *$ denote significance at the 10,5 , and 1 percent level. 